\title{
Comparative analysis of learning in honeybees
}

\author{
M. E. BITTERMAN \\ University of Hawaii, Honolulu, Hawaii
}

\begin{abstract}
The performance of free-flying and harnessed honeybees has been studied in a variety of experiments patterned after those in which learning in vertebrates has been studied--among them experiments on amount, quality, and probability of reward; on compound conditioning and discrimination; and on spatial learning and memory. Despite the remoteness of the evolutionary relationship and the vast differences in brain size and structure, the results for honeybees are strikingly similar to those for vertebrates in many respects and different in only a few. The extent to which phenomena of learning common to honeybees and vertebrates can be understood in terms of common functional principles and mechanisms remains to be determined. None of the differences in the results for honeybees and vertebrates points unmistakably to a difference in their learning.
\end{abstract}

Although invertebrate species far outnumber the vertebrates, there has been little study of their learning. Psychologists have not been much interested in invertebrates, and zoologists interested in invertebrates have not been much interested in learning. It is difficult, in fact, to find an invertebrate species with which to do systematic work on learning - available in large numbers, easily maintained in or near the laboratory, and with suitable sensory, motor, and motivational properties. Fortunately, however, there are the honeybees-long known to meet those requirements (Frisch, 1914, 1919)-whose performance has begun in recent years to be surveyed in a variety of experiments analogous to those designed for the study of learning in vertebrates (Bitterman, 1988).

The first decade or so of the survey showed no uniqueness in the learning of honeybees, but only a wide range of phenomena familiar from the work with vertebrates, which was surprising in view of the fact that the common ancestor of honeybees and vertebrates lived about a half billion years ago and must hardly have had any brain at all. On Simpson's (1964) assumption that convergence to the point of identity or even of seriously confusing similarity is rather unlikely in elaborately polygenic behavioral systems, it was easy nevertheless to expect that many of the resemblances would prove on further analysis to be no more than superficial. Almost from the outset, therefore, the work was shaped by two conflicting interests, one in broadening the survey, and the other in stopping to probe at least some of the more intriguing resemblances as they appeared.

This work was supported by a series of grants (currently, IBN9308132) from the National Science Foundation. I am indebted to my colleague, Patricia A. Couvillon, who played an important part in it almost from the beginning. Correspondence should be addressed to M. E. Bitterman, Békésy Laboratory of Neurobiology, 1993 EastWest Road, Honolulu, HI 96822 (e-mail: jeffb@ahi.phrc.hawaii.edu).

Note: This article is one of those occasionally invited by the editor in which authors have the opportunity to provide an overview of their research programs.--Editor
More recent experiments have shown not only further similarities in performance, but also some differences, which themselves require careful analysis. Since performance in learning situations is not determined by learning alone, a difference in the performance of two animals trained under presumably analogous conditions does not necessarily reflect a difference in their learning (Bitterman, 1960, 1975). Given the substantial number of alternative explanations to be ruled out, it certainly is no less demanding a task to establish a difference in the learning of two animals than to establish that their learning is the same. Just how demanding has not been appreciated sufficiently by the confident denigrators of traditional "general process" learning theory, who (together with any remaining traditionalists) might find it instructive to sample the results for honeybees.

Chosen for consideration here are, first, some experiments on parameters of reward (amount, quality, and probability), the results of which are similar in many respects to those for vertebrates; next, some experiments on compound conditioning and discrimination whose results are different at least in one important respect from those for vertebrates; and, finally, some experiments on spatial learning and memory whose results bear on several matters, among them the issue of adaptive specialization in learning.

\section{PARAMETERS OF REWARD: AMOUNT}

A foraging honeybee rewarded with sucrose solution for landing on a distinctive target (sometimes characterized as an artificial flower) will land more readily on that target when encountering it again. The change in behavior prompts a series of questions, familiar from the vertebrate literature, about the parameters of reward and about what is learned.

A method commonly employed in experiments on the role of amount of reward has been to train individual foragers with targets of two different colors or two different odors, a target of one color or odor containing a 20- $\mu$ ldrop 
of $50 \%$ sucrose solution and the other a $5-\mu$ drop of the same solution (Couvillon \& Bitterman, 1993; Couvillon, Lee, \& Bitterman, 1991). The targets are presented singly and in balanced quasi-random sequences on the sills of two adjacent laboratory windows between which the animal learns to shuttle. Arriving from the hive on each visit to the laboratory, the animal finds one or the other of the targets in one or the other of the windows. After landing and taking the sucrose, it flies up from the target, which is then removed, and goes to the alternative window, where in the meantime a second target has been placed. While the animal is taking sucrose on the second target, the target in the first window is replaced, and so forth. When the animal is replete - that is, after it has ingested about $50 \mu \mathrm{l}$ of the sucrose solution-it goes back to the hive of its own accord to deposit the sucrose and several minutes later returns to the laboratory, again of its own accord, for another series of trials. On the visit following the last scheduled training visit, there is an unreinforced preference test with the two targets presented as a pair on the sill of one of the windows, each target now containing a 10$\mu l$ drop of water. The water, which is unacceptable to the animal, can be distinguished from the sucrose solution only by taste. Encountering the water on one of the targets, the animal leaves the target, then returns to it or goes to the other, leaves again, returns again (often only briefly, with no attempt to drink), and so forth, the interval between successive responses increasing progressively as the test continues. All contacts with each target in a 10min period are recorded.

In Figure 1, the test results for three groups of animals trained with targets differing in odor are plotted in terms of the mean cumulative frequency of response over successive 30-sec intervals (Couvillon, Lee, \& Bitterman, 1991). As the curves show, the $20-\mu$ l odor was clearly preferred to the $5-\mu 1$ odor by Group 8-8, which had eight training trials with each; and by Group 16-16, which had 16 trials with each; but not by Group 8-16, which had eight trials with the $20-\mu$ lodor and twice that number of trials with the 5- $\mu$ lodor. One way to account for these results is on the assumption that odors and amounts are associated-the two associations differing not only in their first terms but also in their second terms (or significates)-and that choice is based on remembered or "represented" (associatively reinstated) amounts. The tradeoff with frequency would suggest, however, that choice depends not only on what is represented but in some sense also on the strength of the representation. A more parsimonious (nonrepresentational) interpretation is that the two odors have a common significate (say, sweet taste) and that choice is based on associative strength, which grows as a function both of frequency and amount of reward (Hull, 1943; Rescorla \& Wagner, 1972).

The results of initial experiments (Buchanan \& Bitterman, 1989) suggested that the effect of amount of reward is only on the rate of growth in associative strength (the equal-asymptote assumption), which if true would argue

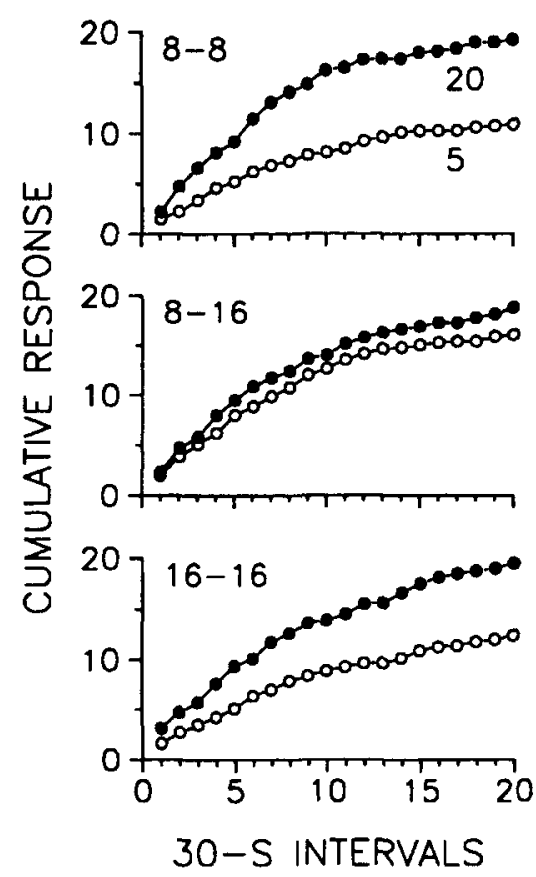

Figure 1. Cumulative number of responses in an unreinforced choice test with two targets different in odor that previously contained 20- or 5- $\mu$ l drops of 50\% sucrose solution. Group 8-8 had eight training trials with each odor, Group 16-16 had 16 trials with each, and Group 8-16 had 8 trials with the 20- and 16 trials with the 5- $\mu$ odor.

against a representational interpretation. It would be difficult to understand in representational terms why a preference exhibited after a small number of trials should disappear with continued training; in rats and monkeys, initial preferences seem to persist indefinitely (Davenport, 1970). Soon, however, the results of reversal experiments with honeybees pointed to asymptotic inequality. For the subjects of one such experiment (Couvillon, Lee, \& Bitterman, 1991), there were $2420-\mu$ trials with one odor intermixed with the same number of $5-\mu l$ trials with a second odor, after which there were 48 additional trials with the odor-amount relationship reversed. In a subsequent test, as Figure 2 shows, the 5-20 odor (the odor for which the amount of reward was changed from the smaller to the larger) was clearly preferred, although the terminal associative strengths produced by reversal training should have been exactly the same if the acquisition functions for the two amounts of reward differed only in rate of approach to a common asymptote.

The preference for the 5-20 odor is open also, of course, to a representational interpretation, which may be perfectly appropriate to the like results of analogous experiments with rats (Capaldi \& Lynch, 1967) because there is independent evidence from contrast experiments of learning "about" amount of reward in rats. In an early experiment by Crespi (1942), for example, the runway performance of rats trained with large reward was found to 


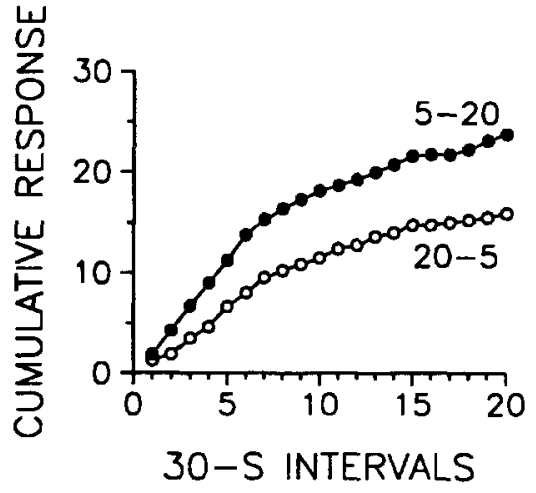

Figure 2. Cumulative number of responses in an unreinforced choice test with two targets different in odor, one (5-20) having previously contained first 5-and then $20-\mu$ l drops of $50 \%$ sucrose solution, and the other (20-5) the two amounts in the opposite sequence.

be sharply disrupted by a shift to small reward, falling considerably below that of control animals trained from the outset with the small reward. For honeybees, there is as yet no such evidence and no good reason, therefore, to abandon the (simpler) nonrepresentational interpretation. Although (where the course of acquisition is different) asymptotic equality would appear to rule out a representational interpretation, asymptotic inequality does not in itself require one. Like rats, goldfish perform better for large than for small reward, but when shifted from large to small reward they give no sign of disturbance and may even continue to perform better than control animals trained from the outset with the small reward (Lowes \& Bitterman, 1967). Vertebrate experiments suggest that the modulation of instrumental performance by its remembered and anticipated consequences first appeared in some common reptilian ancestor of birds and mammals (Bitterman, 1987).

How honeybees discriminate amount of reward has not been determined. One possibility is that the duration of the consummatory response is important; the preference for a color or an odor paired with a given amount of sucrose may increase with the duration of concurrent colorsucrose or odor-sucrose stimulation, which is greater for a larger amount than for a smaller because it takes longer to ingest. This explanation implies the possibility of excitatory conditioning with strictly simultaneous pairing of odor and sucrose, which has in fact been demonstrated with a Pavlovian technique developed by Frings (1944) that permits better control of stimulation than is possible in work with free-flying subjects. In one experiment (Batson, Hoban, \& Bitterman, 1992), foragers harnessed as shown in Figure 3 were differentially conditioned with odors $(\mathrm{S}+$ and $\mathrm{S}-$ ). For a forward group, $\mathrm{S}+$ was followed immediately by sucrose; for a simultaneous group, $\mathrm{S}+$ and sucrose were presented simultaneously; and for both groups, $\mathrm{S}-$ was presented without sucrose. Then there were unreinforced test trials with each of the odors. The left portion of Figure 4 shows rapid conditioning of proboscis-extension to $\mathrm{S}+$ in the forward group, but little response to $\mathrm{S}-$ in either group on the training trials. The right portion shows substantial response to $S+$ in the simultaneous group (which had never before encountered that stimulus alone), although not as much as in the forward group, and no response to $\mathrm{S}-$ by either group on the test trials. Given the control for sensitization inherent in the procedure, differential response to the two odors in the simultaneous group demonstrates simultaneous conditioning. Further experiments (Hoban, Couvillon, \& Bitterman, 1996) have confirmed these results but have failed to show any effect of the duration of concurrent odor-taste stimulation, suggesting that contiguous onset is the critical factor in simultaneous conditioning and that an explanation of how amount of reward is detected should be sought elsewhere.

It may be well to note in passing that the proboscisextension conditioning technique has yielded an extensive array of Pavlovian phenomena familiar from work with vertebrates. For example, the explicitly unpaired procedure traditionally employed to control for exposure to the conditioned and unconditioned stimuli apart from their contiguity has been found to retard acquisition when the two stimuli are subsequently paired, and the effect of pairing apart from the possibility of adventitious responsereinforcer contiguity has been demonstrated with an omission procedure (Bitterman, Menzel, Fietz, \& Schäfer, 1983). An interesting disadvantage of the technique is that visual stimuli (which are otherwise so useful in learning experiments with free-flying subjects) fail to elicit the proboscis response. The source of the difficulty does not seem to be that the animals are harnessed, but that they are stationary, nor is the differential conditionability of stationary and flying foragers limited to visual stimuli. Foragers feeding on a baited target quickly learn to avoid shock by leaving the food when the shock is signaled by an air stream or by substrate vibration, but not when it is signaled either by lights or by changes in the
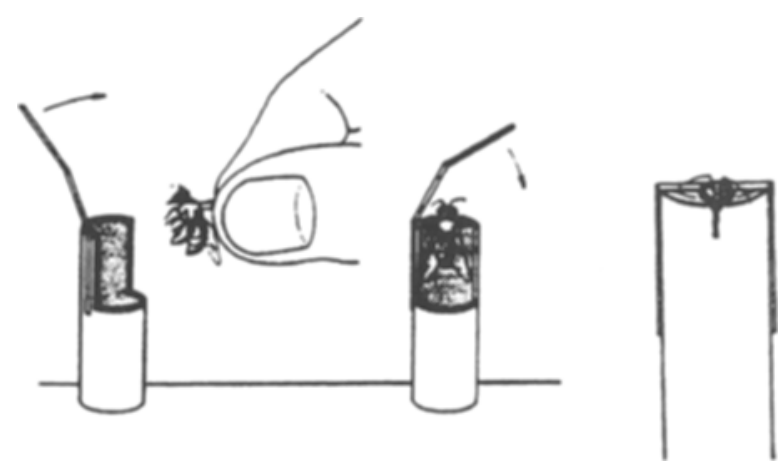

Figure 3. Harnessing technique used in the conditioning of proboscis-extension. A second piece of thin flat tape, not shown, runs horizontally behind the animal. 


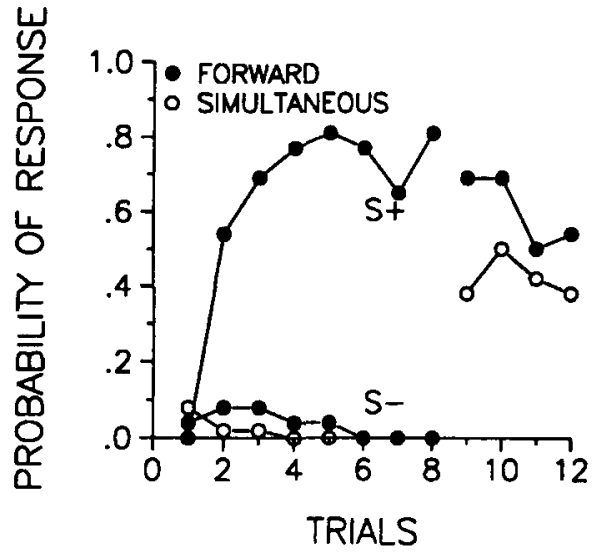

Figure 4. Differential conditioning of proboscis-extension with the positive odor $(\mathbf{S}+)$ either antedating the unconditioned stimulus (forward) or presented simultaneously with it. The first eight trials with each stimulus were training trials and the last four were unreinforced test trials.

magnetic field (constant or time varying) that are readily discriminated by flying animals (Walker, Baird, \& Bitterman, 1989); the magnetic sensitivity displayed by flying foragers is, in fact, remarkable (Walker \& Bitterman, 1989). The explanation of these results probably is to be found, not in the learning of honeybees, but in the way in which they process visual and magnetic stimuli. It is interesting that pigeons, too, detect magnetic stimuli while flying but fail to respond to them when confined in a small enclosure (Couvillon, Asam, \& Bitterman, 1992).

\section{PARAMETERS OF REWARD: QUALITY}

Unlike the results for amount of reward, the results for quality of reward (concentration of sucrose) do point in some cases to representation, perhaps because concentration, which is detected immediately upon contact, is a more salient property of reward. It may be well to note, too, that critical information about concentration is provided by measures of performance that are not informative with respect to amount. The unreinforced preference test, which is useful in experiments both on amount and on concentration, is cumbersome, having the great disadvantage that multiple groups are required to chart the course of acquisition; to train and test the same animals repeatedly (e.g., Menzel, 1967) would be to confound the effects of reinforcement and nonreinforcement. Latency of shuttling in the two-window situation - the natural log time (in seconds) between leaving the target in one window and landing on the target in the alternative windowdoes provide a proper trial-by-trial measure of the course of acquisition, which for unknown reasons is sensitive to differences in concentration of sucrose but not to differences in amount. In the case of concentration, some important information is also provided by observations of consummatory behavior.
Shown in Figure 5 are the results of an experiment in which individual foragers were trained with successively presented targets of two different odors, a target of one odor containing a $5-\mu \mathrm{l}$ drop of $50 \%$ sucrose solution and the other a $5-\mu \mathrm{l}$ drop of $20 \%$ sucrose solution (Loo \& Bitterman, 1992). Latency of response declined progressively over successive visits to a lower level on trials with the $50 \%$ odor than on trials with the $20 \%$ odor, results that are immediately reminiscent of the relation between asymptotic running speed and concentration of sucrose found in runway experiments with rats (e.g., Goodrich, 1960). The impression of an asymptotic difference was confirmed in a reversal experiment both by a crossover of the latency curves and by greater response in a subsequent preference test to the odor paired most recently with $50 \%$ sucrose. In addition to the prospective effect (more rapid responding to a $50 \%$ target than to a $20 \%$ target), the honeybees showed another phenomenon familiar from work with vertebrates that it is convenient to call the retrospective effect: Responding was consistently more rapid after $20 \%$ trials than after $50 \%$ trials.

The vertebrate literature suggests a number of explanations of the retrospective effect. Responding after $20 \%$ reward may have been speeded by something like frustration in rats (Amsel \& Roussel, 1952), although that possibility can perhaps be discounted on the ground that the effect persisted long after the odor discrimination was well established; in rats, the frustration effect is assumed to decline and disappear as expectations come increasingly to correspond with reality (Amsel, 1992). Another possibility is that responding after $50 \%$ reward was slowed by some competing postingestive influenceattraction to the locus of reward, for example, or shortterm "demotivation" (Seward, Pereboom, Butler, \& Jones, 1957). What is commonly called postingestive "inhibition" in the vertebrate literature is inferred from findings such as that the responding of rats in the second alley of a double runway slows in proportion to the amount of

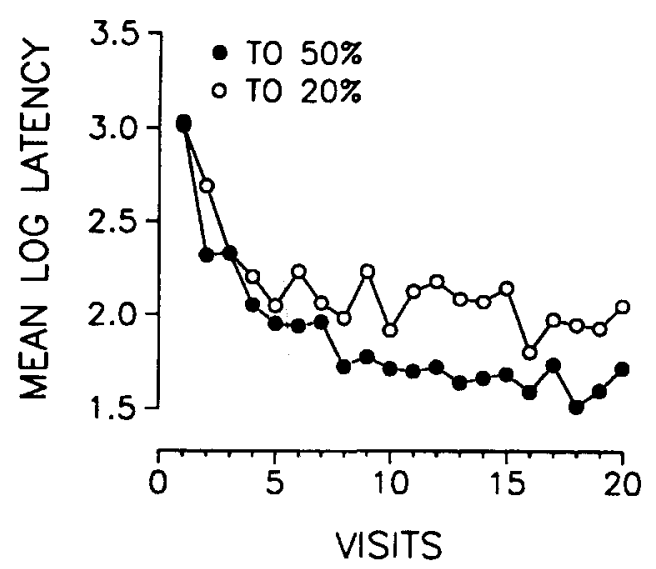

Figure 5. Mean natural log latency of approach to targets of different odor containing drops of $20 \%$ or $50 \%$ sucrose solution. 
food given in the first goalbox (McHose \& Ludvigson, 1965), or that the postreinforcement pausing of pigeons responding for grain on a mixed fixed-interval schedule lengthens in proportion to the duration of access to the feeder (Staddon, 1970). Of special interest in relation to the honeybee results is an experiment by Lowe, Davey, and Harzem (1974) in which the postreinforcement pausing of rats leverpressing for sweetened milk on mixed schedules was found to increase with the concentration of the milk.

In an experiment whose results rule out both possibilities (Couvillon, Nagrampa, \& Bitterman, 1994), honeybees were trained as before except that the odors distinguishing the $20 \%$ and $50 \%$ targets were introduced only on the last 8 of 16 training visits; on the first 8 visits, both the $50 \%$ and $20 \%$ targets were odorless. As Figure 6 shows, there was no retrospective effect before the odors were introduced, whereupon it appeared precipitously, taking the form primarily of slow responding on $50 \%-$ $20 \%$ trials (that is, on trials with the $20 \%$ odor immediately following $50 \%$ trials). Prospective-retrospective interactions suggestive of "transient" contrast (Nevin \& Shettleworth, 1966) have also appeared in the postreinforcement pausing of rats and pigeons trained on multiple (rather than mixed) ratio schedules. In free-operant work with pigeons, Perone and Courtney (1992) found, for example, that pausing was longer after large reward than after small, with the difference considerably greater in the presence of the signal for small reward.

A possibility to be considered is that the retrospective effect in honeybees has an associative basis. If, owing to sensory adaptation, $20 \%$ sucrose tastes less sweet after $50 \%$ sucrose than after $20 \%$ sucrose and therefore is less reinforcing (Couvillon \& Bitterman, 1984), there may have been less reinforcement of response to the $20 \%$ odor in compound with the aftertaste of $50 \%$ sucrose and/or a trace of the $50 \%$ odor $(50 \%-20 \%$ trials) than in compound

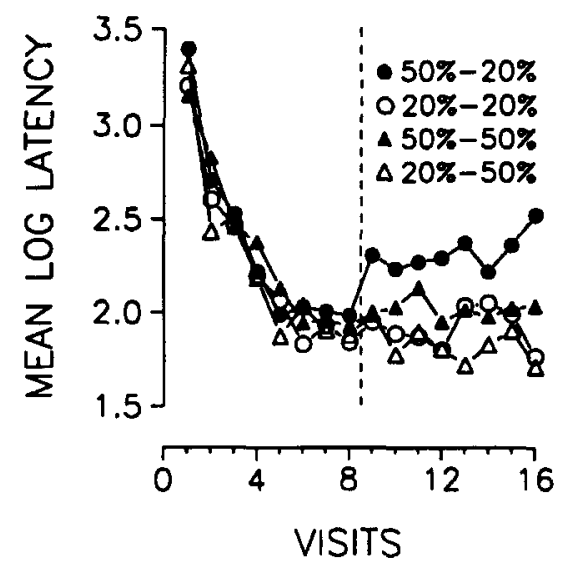

Figure 6. Mean natural $\log$ latency of approach to a target containing $20 \%$ sucrose solution after a trial with a target containing $50 \%$ solution $(\mathbf{5 0} \%-\mathbf{2 0} \%), \mathbf{2 0} \%$ after $20 \%(20 \%-20 \%), 50 \%$ after $50 \%(50 \%-50 \%)$, and $50 \%$ after $20 \%(20 \%-50 \%)$. The $20 \%$ and $50 \%$ targets were unlabeled on the first eight visits and labeled with different odors thereafter.

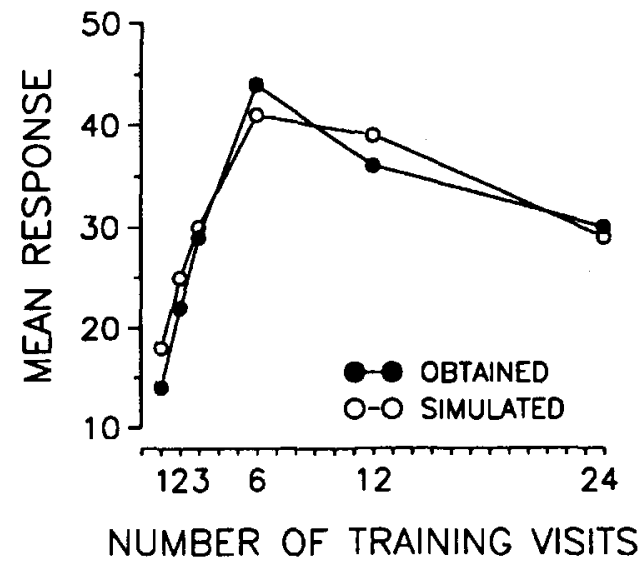

Figure 7. Resistance to extinction (filled circles) as a function of the number of training visits with feeding to repletion on $50 \%$ sucrose solution as reward. The open circles show a simulation of the data with a frustration model.

with the aftertaste of $20 \%$ sucrose and/or a trace of the $20 \%$ odor $(20 \%-20 \%$ trials). Efforts to find direct evidence of adaptation-based differential reinforcement have thus far, however, been unsuccessful (Couvillon et al., 1994). In one experiment, for example, foragers were trained with targets of two different odors, both containing $20 \%$ sucrose, and unscented targets that contained $20 \%$ sucrose on some trials and $50 \%$ sucrose on others. Although the sequence was such that trials with one of the odors always followed $20 \%$ trials and trials with the other odor always followed $50 \%$ trials, there was no indication of differential response to the odors, either during training or in a subsequent preference test. What seems to be left, then, is a contrast interpretation, implying that the concentration predicted by the odor encountered on a given trial is evaluated in relation to some temporarily persisting correlate of the concentration encountered on the immediately preceding trial.

There is also evidence that the sucrose concentration actually encountered on a given target is evaluated in relation to the concentration anticipated on the basis of previous experience with that target. This evidence comes indirectly from work on a phenomenon found in honeybees (Couvillon \& Bitterman, 1980, 1984) that is like the vertebrate "overlearning-extinction effect" (Ison \& Cook, 1964). In Figure 7, resistance to extinction (number of responses in a 10-min test period to a distinctive target containing a large drop of water) is plotted (filled circles) for six groups of foragers that had different numbers of training visits to the target; the reward on each training visit was feeding to repletion from a large drop of $50 \%$ sucrose solution. Evidence that the decline in resistance to extinction with increases in the number of training visits from 6 to 12 and 24 is not attributable to reduced hunger is provided by an experiment in which one group of foragers had 18 visits to a distinctive target (A) while another had six visits to $A$ intermixed with 12 visits to a different target (B); although the nutritive levels of the two groups 
were the same, the first showed much less resistance than the second when both were extinguished with A (Shinoda \& Bitterman, 1987).

The nonmonotonic relation between number of training visits and resistance to extinction is easily modeled (Figure 7, open circles) on two assumptions: One is that associative strength $(V)$ increases with reinforcement and decreases with nonreinforcement in simple monotonic fashion; the second is that $\mathrm{F}$, a competing response akin to Amsel's frustration, is generated by unrealized expectation of reward as a function of $\mathrm{V}-\mathrm{M}$, with $\mathrm{M}$ conceived as the minimal value of $\mathrm{V}$ required for the development of $F$ on an extinction trial (Couvillon \& Bitterman, 1991). The analysis suggests that resistance to extinction will increase monotonically with the number of training visits if the sucrose concentration is low enough for $\mathrm{V}$ never to exceed $\mathrm{M}$, and an experiment with $50 \%$ versus $20 \%$ sucrose has in fact shown the overlearning-extinction effect with the higher concentration but not with the lower (Couvillon \& Bitterman, 1984). The overlearningextinction effect in rats has also been found to depend on large reward (Ison \& Cook, 1964).

The effect of unrealized anticipation can be seen more directly in the disrupted consummatory behavior of honeybees that have repeatedly been fed $50 \%$ sucrose on one target (A) and $20 \%$ sucrose on another (B) when for the first time they encounter $20 \%$ sucrose on target $A ; 20 \%$ sucrose is taken somewhat less readily than $50 \%$ sucrose even on target B, but much less readily on target A (Couvillon \& Bitterman, 1984). This phenomenon looks very much like the incentive contrast that has been found in the consummatory behavior of rats (Flaherty, Becker, \& Checke, 1983) and opossums (Papini, Mustaca, \& Bitterman, 1988). In both cases, subjects trained with a sucrose solution of high concentration and tested with a solution of lower concentration found the lower concentration less acceptable than did control subjects trained with the lower concentration. In an analogous experiment, goldfish failed as always to show contrast, persistently taking more of a less preferred solution after training with a preferred solution than did control subjects trained with the less preferred solution (Couvillon \& Bitterman, $1985 b$ ). A reasonable inference from the vertebrate results is that the mechanisms of incentive contrast in honeybees and mammals (whatever they may be) have evolved independently.

\section{PARAMETERS OF REWARD: PROBABILITY}

Evidence of divergence in vertebrate learning also comes from experiments on resistance to extinction as a function of probability of reward (Bitterman, 1987). Trained in widely spaced trials and with large reward, birds and mammals show greater resistance after inconsistent ("partial") than after consistent reinforcement (the partial reinforcement effect), but vertebrates of older lines do not. Where trials are massed, the greater resis-

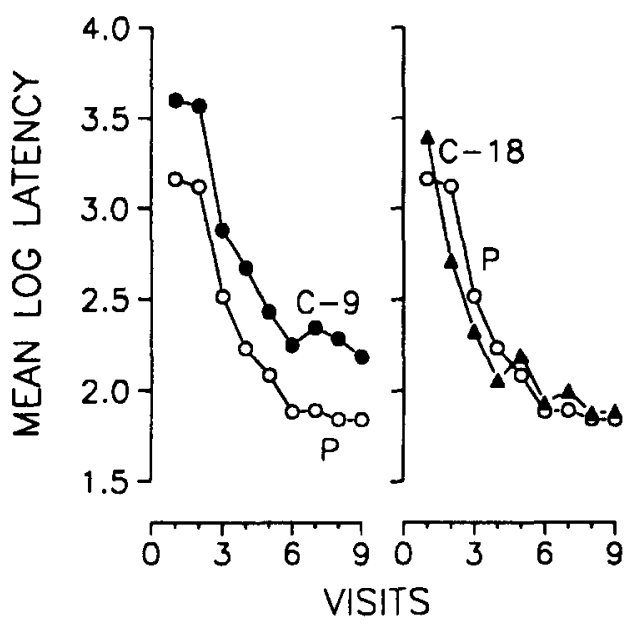

Figure 8. Acquisition of a shuttling response in a partially reinforced group (P) compared (left panel) with acquisition in a consistently reinforced group (C-9) given the same number of reinforced trials and (right panel) with acquisition in a consistently reinforced group (C-18) given the same total number of trials as Group $P$ in twice the number of visits. The curves are plotted in terms of mean natural log latency of a shuttling response in successive visits or (for Group C-18) pairs of visits.

tance of partially reinforced animals is attributable to frequent reward in training for response to transient aftereffects of nonreward that carry over from trial to trial and are subsequently encountered by both groups in extinction (Sheffield, 1949). Where trials are widely spaced, eliminating carryover, the effect can be understood in terms of the conditioning and counterconditioning of frustration that is generated by unrealized expectation of large reward (Amsel, 1992). All vertebrates tested show the partial reinforcement effect in massed trials, and the results for honeybees, trained of necessity with relatively short intertrial intervals, are much like those for vertebrates in general.

In one experiment (Ishida, Couvillon, \& Bitterman, 1992), foragers shuttling between two adjacent windows found unscented targets of a single color containing 10- $\mu$ l drops of 50\% sucrose solution on some (R) trials and 10 $\mu$ drops of water on other (N) trials. The left panel of Figure 8 shows the course of acquisition in terms of mean natural $\log$ latency of response per trial on successive visits for two groups of foragers (C-9 and $\mathrm{P}$ ) that had nine training visits. For Group C-9, responding was consistently reinforced in training; each animal in the group had 45 $\mathrm{R}$ trials in all. For Group P, responding was partially reinforced; for each animal in the group, $45 \mathrm{~N}$ trials were interspersed quasi-randomly among its $45 \mathrm{R}$ trials, making 90 trials in all. As the curves show, the performance of Group P was better than that of Group C-9, a familiar vertebrate phenomenon; in Notterman's (1951) runway experiment with rats, for example, running speed in acquisition increased with the number of added $\mathrm{N}$ trials over a wide range. The right panel of Figure 8 shows acquisition in Group P along with acquisition in another consis- 
tently reinforced group (C-18), which had the same number of trials ( $90 \mathrm{R}$ trials) in 18 training visits, and whose performance is plotted over pairs of visits; the two curves are much the same, which is to say that the unreinforced trials contributed as much to performance as the reinforced trials. It was suggested early in the vertebrate literature that $\mathrm{N}$ trials improve performance because of secondary reinforcement (Denny, 1946). For honeybees, the independent evidence of secondary reinforcement is still only fragmentary (Grossmann, 1971), although secondorder appetitive conditioning has clearly been demonstrated with the proboscis-extension technique (Bitterman et al., 1983) in an experiment patterned directly after work with rats (Holland \& Rescorla, 1975).

In Figure 9, the performance of Groups P, C-9, and C18 in extinction (all targets now containing $10-\mu 1$ drops of water) is plotted in terms of the mean cumulative number of shuttling responses over successive 30 -sec intervals of a 15 -min period. If secondary reinforcement on the added $\mathrm{N}$ trials can be thought to have increased associative strength in Group $\mathrm{P}$, its greater resistance to extinction as compared with that of Group C-9 may seem to present no special problem. More interesting is the finding that resistance to extinction was greater in Group $P$ than in Group C-18, which had the same total number of training trials and twice the number of $R$ trials. Here we have what looks like the vertebrate "equated-trials" partial reinforcement effect, for which an explanation in terms of secondary reinforcement is ruled out, but which can readily be explained in terms of carryover.

Independent evidence of the discriminative control of performance by lingering traces of reward and nonre-

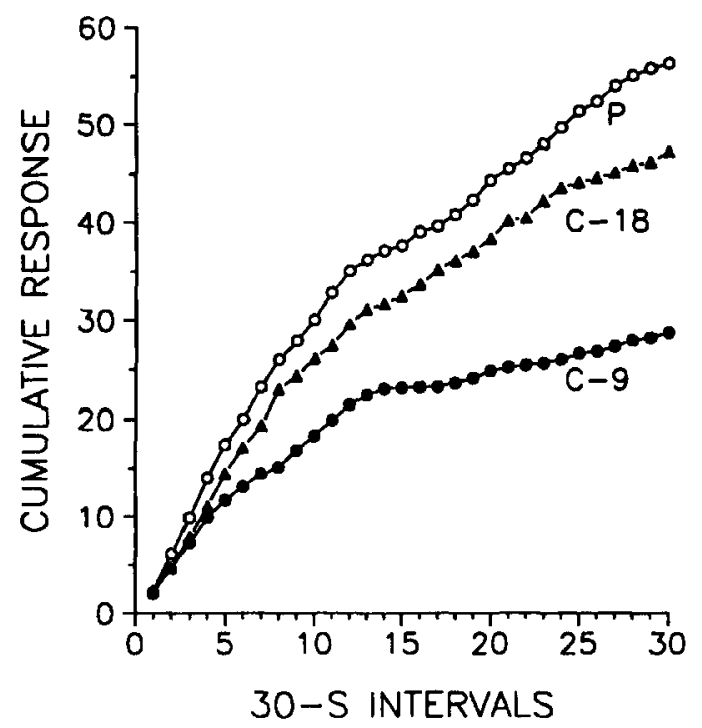

Figure 9. Cumulative number of shuttling responses in extinction for a partially reinforced group $(P)$, a consistently reinforced group (C-9) given the same number of reinforced training trials, and a consistently reinforced group $(C-18)$ given the same total number of training trials. ward was first obtained in a runway experiment with rats (Tyler, Wortz, \& Bitterman, 1953); when R and N trials were singly alternated, slower running after $R$ trials than after $\mathrm{N}$ trials soon appeared, but not when $\mathrm{R}$ and $\mathrm{N}$ trials were scheduled in quasi-random sequence (their aftereffects nondifferentially reinforced). An experiment with honeybees has failed to show single-alternation patterning (Ishida et al., 1992), but a general negative conclusion would be premature because the failure of a phenomenon known in one species to appear in another may mean only that it has not been looked for under equivalent conditions (Bitterman, 1975). In rats, for example, the extent of single-alternation patterning varies markedly with effortfulness of response and amount of reward (Gonzalez, Bainbridge, \& Bitterman, 1966). The Ishida experiment also failed to show increased resistance to extinction with longer runs of $\mathrm{N}$ trials, a vertebrate phenomenon presumably generated by cumulative aftereffects of $\mathrm{N}$ trials (Capaldi, 1964; Gonzalez \& Bitterman, 1964). Foragers repeatedly fed to repletion on a distinctive target have, however, been found to show greater resistance to extinction when on half the training trials the feeding was immediately preceded by several minutes of exposure to the target without food (Couvillon \& Bitterman, 1980). In other experiments (Ammon, Abramson, \& Bitterman, 1986), where reinforced trials with the partial stimulus were never immediately preceded by unreinforced trials with the same stimulus, the partial reinforcement effect could not be found.

Probability of reward has also been studied in choice training (Fischer, Couvillon, \& Bitterman, 1993). Again each animal shuttled between two adjacent windows, but now on each trial it found a pair of targets labeled with different odors, one containing a $10-\mu \mathrm{l}$ drop of $50 \%$ sucrose solution and the other a $10-\mu 1$ drop of water; immediate correction of error was permitted. Some animals were trained with one of the odors always signaling sucrose and the other always signaling water (100:0 training). For others, the training was 100:0 to begin with and then shifted to a different reward ratio, such as 90:10 (one target containing sucrose on only $90 \%$ of the trials, and the alternative target containing sucrose on the remaining $10 \%$ of the trials), $80: 20,70: 30,60: 40$, or $50: 50$ (each of the odors equally often signaling the sucrose). Asymptotic choice probabilities are plotted against reward probabilities in Figure 10 (filled circles), from which can be read, for example, the mean asymptotic probability of choosing the $80 \%$ alternative in $80: 20$ training, or the mean asymptotic probability of choosing the $30 \%$ alternative in 30:70 training. The relation between the two probabilities is clearly linear, with a slope substantially less than 1. Plotted along with the results for honeybees are the results of an early experiment by Estes (1957) with college students (open circles), from which it should be evident that striking similarities in the performance of different animals need not reflect common functional principles; the reports of human subjects studied in such experiments imply intellectual capabilities that sensible peo- 


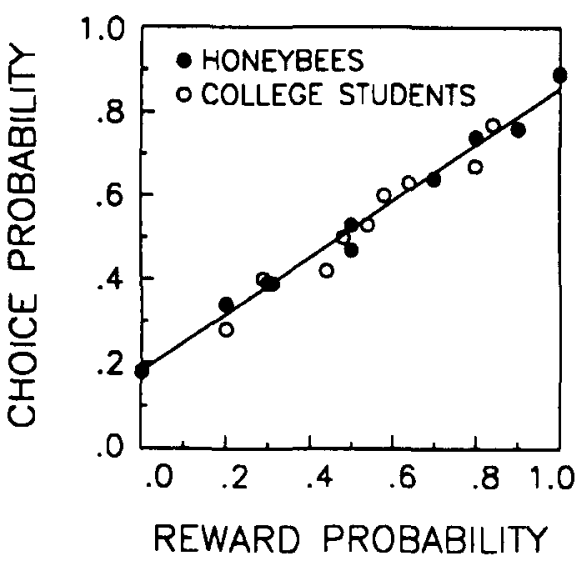

Figure 10. Choice probability as a function of reward probability in honeybees (filled circles) and college students (open circles). The data for college students are taken from Estes (1957). The line shows the relation predicted by a simple theory of discriminative learning in honeybees.

ple would hesitate to attribute to honeybees (Goodnow, 1955).

The results for honeybees plotted in Figure 10 are especially interesting because they were predicted from a simple theory-what Lashley (1942) would have called a "continuity" theory-developed in earlier experiments on simultaneous discrimination (Couvillon \& Bitterman, 1985a, 1986, 1987, 1988). The predicted relation between choice probability and reward probability is shown by the line about which both sets of data cluster. The line was computed independently of the data with two equations, one a linear function describing the growth or decline of associative strength (V) with reinforcement or nonreinforcement, and the other a power function describing the probability of choosing one of two alternatives on the basis of its relative associative strength. The values of the several parameters of the two equations used for the computation (the rates of growth and decline in $\mathrm{V}$ with reinforcement and nonreinforcement, as well as of two parameters determining the shape of the choice function) had already been estimated by fitting the theory to the data of the entire set of earlier experiments.

The strategy in developing the theory was to begin with an array of simple problems and with the simplest assumptions that could account for their results. With the same assumptions, it then proved possible to account for the performance of honeybees in some relatively complex color-odor problems, such as compound-component and conditional discriminations - an animal being required, for example, to choose a blue rather than a green target if both were scented with peppermint, but to choose green rather than blue if both targets were scented with geraniol (Couvillon \& Bitterman, 1988). The same theory has been found to account for the performance of vertebrates in a problein that might seem intuitively to be even more complex. Von Fersen, Wynne, Delius, and Staddon (1991) trained pigeons to discriminate concurrently between five stimuli (A, B, C, D, and E) differentially reinforced in four pairs: $\mathrm{A}+\mathrm{B}-, \mathrm{B}+\mathrm{C}-, \mathrm{C}+\mathrm{D}-$, and $\mathrm{D}+\mathrm{E}-$. Tested then with $\mathrm{BD}$, the animals preferred $\mathrm{B}$-that is, they showed "transitive inference"-an outcome that in work with primates has been interpreted in symbolic terms (Gillian, 1981) but that can be simulated rather exactly with the two honeybee equations (Couvillon \& Bitterman, 1992a). The effort at simulation was prompted by the idea that nothing more might be required by the four-pair problem than by the two-pair "ambiguous-cue" problem $(\mathrm{A}+\mathrm{B}-, \mathrm{B}+\mathrm{C}-$ ), in which the performance of honeybees had already been described and accurately simulated (Couvillon \& Bitterman, 1986).

\section{COMPOUND CONDITIONING}

Although it is hardly to be supposed that discriminative learning in vertebrates can be understood entirely in terms of functional principles discernible in the performance of honeybees, just which vertebrate data require different principles and what different principles they may require are questions that can perhaps best be answered in formal efforts to simulate the data on the basis of the simplest possible assumptions. The honeybee theory is itself still in the process of development, and it does not yet encompass even some vertebrate phenomena already mirrored in the performance of honeybees. One of them is the phenomenon discovered by Pavlov (1927) that came to be known in the vertebrate literature as "transfer along a continuum" (Lawrence, 1952). For example, naive honeybees may fail to detect small anomalies in the ambient magnetic field that they can detect readily after successful training with larger anomalies (Walker, Lee, \& Bitterman, 1990). To account for the phenomenon, several different principles have been invoked, none of which has yet been incorporated in the developing honeybee theory. One of them is the principle of stimulus generalization, which certainly will have to be incorporated. Another is the principle of selective attention, which may be required by the results of experiments on compound conditioning.

A simple assumption incorporated in the honeybee theory is that the associative strength of a compound stimulus is equal to the sum of the strengths of its components. The assumption is not contradicted by the finding that compounds may have properties distinct from the properties of their components, which is evident from the solution of conditional problems (Couvillon \& Bitterman, 1988), and which can be demonstrated even without differential reinforcement. For example, foragers that have been fed on some visits on a target (OJ) that is orange $(\mathrm{O})$ in color and scented with jasmine $(\mathrm{J})$, and fed on other visits on a target (YV) that is yellow (Y) in color and scented with violet $(V)$, show a distinct preference for the old compounds (OJ and YV) over new compounds (OV and YJ) composed of the same (regrouped) components (Couvillon \& Bitterman, 1982). The honeybee the- 
ory makes it possible to simulate such results on the assumption of compound-unique components generated by afferent interaction that are somewhat less salient than primary components but that function in the same way; the concept of compound-unique components is taken, of course, from the ever-helpful vertebrate literature (Rescorla, 1972; Whitlow \& Wagner, 1972).

Another simple assumption incorporated in the honeybee model is that the components of a compound stimulus gain or lose associative strength independently with reinforcement or nonreinforcement of the compound. Experiments with color-odor compounds give no reason to be dissatisfied with the independence assumption, although in the vertebrate literature it has long been rejected in favor of the assumption that the components compete for associative strength (Rescorla \& Wagner, 1972) or for attention (Sutherland \& Mackintosh, 1971). Honeybees trained with color-odor compounds do show overshadowing, a phenomenon generally believed to contradict the independence assumption, but which does not necessarily do so. For example, greater response to an unscented orange target after training with that target than after training with an orange target scented with jasmine is readily explained in terms of the greater similarity of training and testing conditions (Couvillon \& Bitterman, 1980).

In an overshadowing experiment designed to forestall an explanation in terms of generalization decrement, foragers were trained to choose between two simultaneously presented targets differing in color and odor (Couvillon \& Bitterman, 1989). For an overshadowing group, color and odor were "confounded," which is to say that both were correlated with reinforcement (e.g., blue-geraniol positive and green-peppermint negative), while a control group was trained with odor relevant and color irrelevant (e.g., bluegeraniol positive and green-peppermint negative on half the trials, green-geraniol positive and blue-peppermint negative on the rest). Then there was an unreinforced test with the two odors apart from the colors, in which the overshadowing group showed poorer discrimination than did the control group. In a companion experiment, discrimination of the colors apart from the odors was found to be poorer after confounded training than after control training with color relevant and odor irrelevant - that is, the overshadowing was reciprocal. Initial impressions to the contrary, however, the independence assumption is not contradicted by these results. With parameter values chosen on the basis of previous experiments with the same stimuli, it was predicted from the honeybee theory that the confounded problem would be less difficult than the control problems, and that the confounded animals, having had less unreinforced experience with the negative colors and odors, would discriminate less well in the tests. In Figure 11, the pooled test results for the overshadowing and control groups (filled circles) are plotted along with the theoretical expectations (open circles).

Blocking, which poses a more serious challenge to the independence assumption, has failed to appear in a long series of experiments with color-odor compounds (Funa-

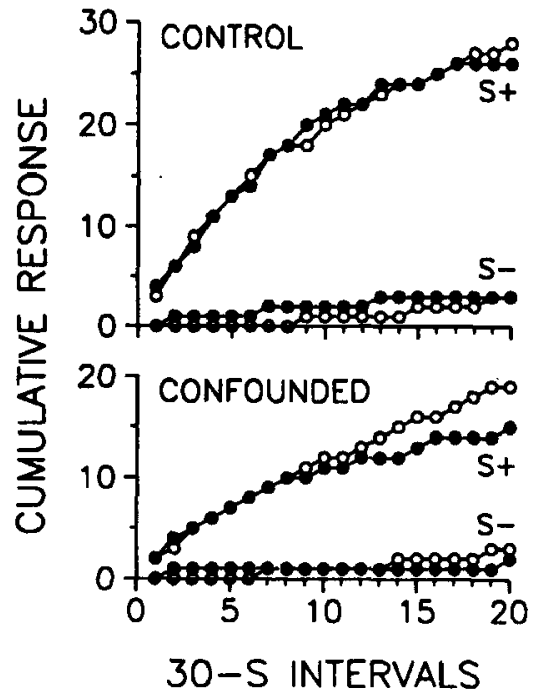

Figure 11. Cumulative number of responses (filled circles) in an unreinforced choice test with targets of two different colors or two different odors $(S+$ and $S-$ ) that had been differentially reinforced in training with color-odor compounds. For control animals tested with the colors, the odors had been nondifferentially reinforced; for control animals tested with the odors, the colors had been nondifferentially reinforced. For the confounded animals, both the colors and the odors had been differentially reinforced. Expectations from a simple continuity theory are also shown (open circles).

yama, Couvillon, \& Bitterman, 1995). In an experiment of single-group design like an autoshaping experiment that showed blocking in pigeons (Rescorla, 1981), foragers were trained to choose between unscented blue and green targets presented simultaneously (e.g., blue positive and green negative); then they were trained with targets of the same two colors presented successively in quasi-random sequence, one scented with peppermint, the other with geraniol, and both reinforced (e.g., bluepeppermint positive and green-geraniol positive); finally, there was a preference test with two gray targets, one scented with peppermint (the prospectively blocked odor in the example given) and the other with geraniol (control). On the independence assumption, equal response to the two odors (equally reinforced in the second stage) was to be expected, and that is what was observed; the conditioning of peppermint did not seem to be impaired by the presence of the previously reinforced blue.

It is possible in such an experiment for a blocking effect to be masked by within-compound association, which has been demonstrated in honeybees (Couvillon \& Bitterman, 1982) in much the same way as in vertebrates (Rescorla \& Cunningham, 1978). Training with the compounds may have tended to enhance the attractiveness of peppermint relative to geraniol because of the opportunity provided for within-compound association of peppermint with blue (previously reinforced) and of geraniol with green (previously unreinforced). In a companion experiment suggested by vertebrate work on overshadowing and 
unblocking (Durlach \& Rescorla, 1980; Rescorla \& Colwill, 1983), an effort was made to minimize the contribution of within-compound association by the use of an interpolated extinction procedure. The design was the same as before, except that the test with the odors was preceded by unreinforced trials with the colors that were designed to reduce their differential attractiveness, but again, as Figure 12 shows, response to the two odors was the same.

Although the results of these and a wide variety of other experiments with color-odor compounds (Couvillon \& Bitterman, 1991) give no reason for dissatisfaction with the independence assumption, the results of some experiments with color-position compounds do seem to contradict it. Both in color-odor and in color-position training, the animals choose between two targets in different positions (say, to the left or to the right of the approaching subject), but in color-odor training position is nondifferentially reinforced. In one of the color-position experiments (Couvillon, Klosterhalfen, \& Bitterman, 1983), reciprocal overshadowing appeared even though the confounded problem (e.g., green-left positive and blue-right negative) was no easier than the color-relevant problem (e.g., green-left positive and blue-right negative on some trials, green-right positive and blue-left negative on the rest) or the position-relevant problem (e.g., green-left positive and blue-right negative on some trials, blue-left positive and green-right negative on the rest). Less was learned about color in the confounded training than in the color-relevant training, and less about position in the confounded training than in the position-relevant training, despite the fact that (because the problems were equal in difficulty) experience with the relevant stimuli was the same in the overshadowing and control groups.

An earlier experiment (Klosterhalfen, Fischer, \& Bitterman, 1978) showed positive intradimensional transfera vertebrate phenomenon that points to competition for attention (Shepp \& Eimas, 1964) - in color-position but

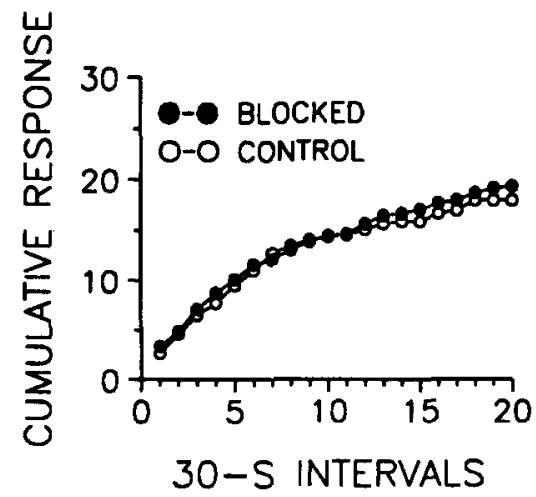

Figure 12. Cumulative number of responses in an unreinforced choice test with two odors after both had been reinforced, one of them (blocked) in the presence of a color itself earlier reinforced, and the other (control) in the presence of a color previously presented without reinforcement.

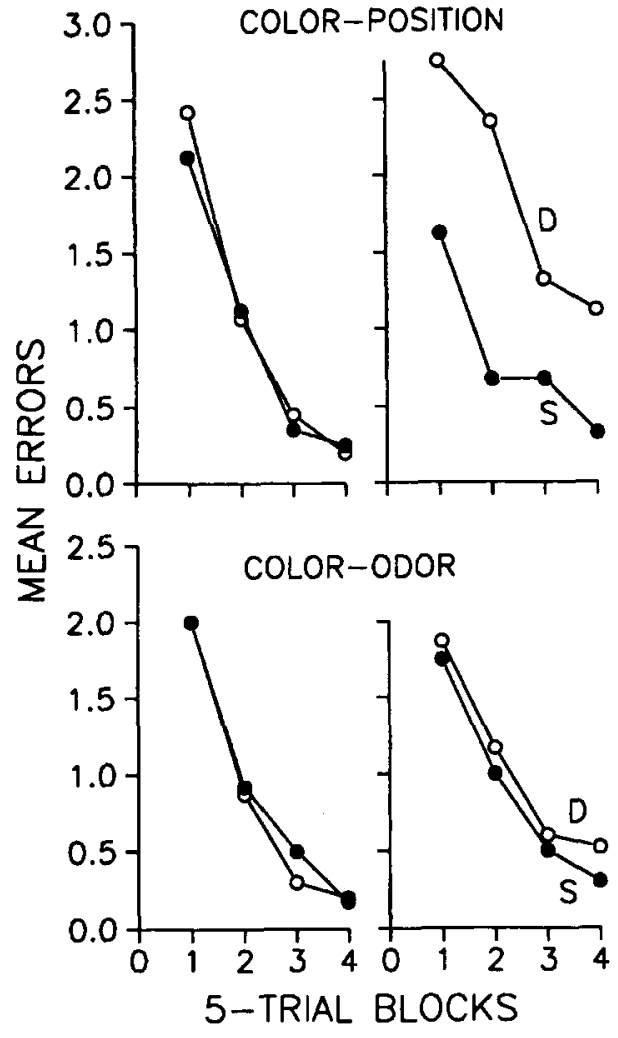

Figure 13. Mean errors per block of training trials in two consecutive color-position problems (top) or color-odor problems (bottom). For Group $S$ in each case, the relevant dimension was the same in the second problem as in the first; for Group D, the relevant dimension of the second problem was the irrelevant dimension of the first.

not in color-odor training. The results are plotted in Figure 13. Foragers trained first in a color-position problem either with color or with position relevant, and then in a second such problem with new colors and new positions, performed better in the second problem when the relevant dimension was the same in the two problems than when it was different. After training in a color-odor problem with color or odor relevant, performance in a second problem with new colors and new odors was the same whether the relevant dimension was the same or different.

Odor and position may not function in the same way when differentially reinforced in compound with color because odor, like color, is an integral property of the target and position is not. It is possible, therefore, that position competes in a special way with target properties for control of performance; a distinctive manner of choice in position-relevant problems - a more direct approach to the positive alternative--was in fact reported in each of the color-position papers (Couvillon et al., 1983; Klosterhalfen et al., 1978). Another possibility, on the assumption that both color and position are given visually, is that intramodal independence is less likely than intermodal 
independence. Much the same proposal has been made by Kehoe, Horne, Horne, and Macrae (1994) on the basis of results for tone-noise compounds versus tone-light and noise-light compounds obtained in conditioning experiments with rabbits. Support for the view that the discrepant honeybee results are better understood in terms of the intramodality of color-position compounds than in terms of their disjunctive (nonintegral) character is provided by evidence of blocking obtained recently in experiments on proboscis-extension conditioning by Smith and Cobey (1994), for whom binary odor mixtures served as odorodor compounds.

Relevant also are the results of some experiments on an unusual intramodal overshadowing effect appearing in experiments on amount of reward. As has already been noted, honeybees trained with successively presented targets of two different colors, one always containing a 20 $\mu \mathrm{l}$ and the other a 5- $\mu \mathrm{l}$ drop of sucrose solution, quickly develop a preference for the 20- $\mu$ l color (Buchanan \& Bitterman, 1989). Because 20- $\mu$ l drops are detected somewhat more readily than are 5- $\mu$ l drops (Walker et al., 1990), it is necessary to control for the possibility that the preference is due, not to the difference in amount of sucrose, but to closer contiguity between the perception of the 20$\mu \mathrm{l}$ color and the initial taste of sucrose, an interpretation supported by the fact that no preference is found when the location of the drop of sucrose at the center of each target is marked with a salient white dot (Lee \& Bitterman, 1990). Figure 14 shows the results of an experiment in which there were 24 trials with each color; animals trained and tested without dots (Group ND-ND)

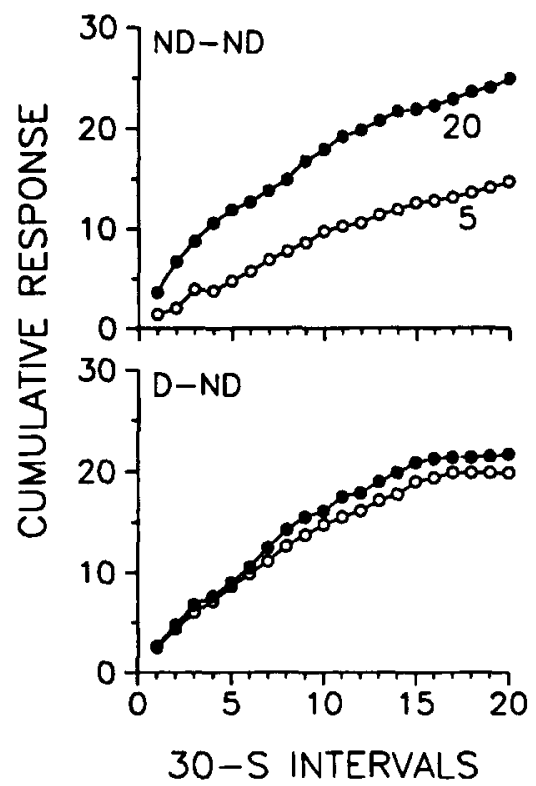

Figure 14. Cumulative number of responses in an unreinforced choice test with two colored targets that previously contained 5or 20- $\mu$ l drops of sucrose solution. During training, the locations of the drops were marked with small white dots for Group D-ND but not for Group ND-ND. preferred the 20- $\mu$ l color, but animals trained with dots and tested without dots (Group D-ND) did not.

Other evidence suggests instead, however, that the colors are overshadowed by the dots, which themselves can be shown to acquire associative strength. The overshadowing interpretation is supported by the fact that a preference for the $20-\mu \mathrm{l}$ color readily appears when delay is equated, not by dotting the conventional flat targets, but by using targets of an inverted conical structure in which the animal is guided by the declining substrate to the location of reward at the base (Couvillon \& Bitterman, 1993). When odors are substituted for colors in experiments with flat targets, a preference for the $20-\mu 1$ odor quickly develops whether or not the targets are dotted (Lee \& Bitterman, 1990; Couvillon, Lee, \& Bitterman, 1991); the reasonable implication of these results is that dots overshadow colors but not odors (intramodal but not intermodal overshadowing).

More recent experiments with a difference in probability $(100 \%$ vs. $50 \%)$ rather than in amount of reward also show dot-color but not dot-odor overshadowing (Couvillon, Mateo, \& Bitterman, 1996). Two groups were trained with targets differing in color, one of the targets always containing a 10- $\mu$ ldrop of sucrose, another containing sucrose on only half the trials, and water on the rest. For one group, the targets were dotted; for the other, they were not. In a subsequent test with undotted targets, the consistently reinforced color was significantly preferred to the partially reinforced color only by the group trained with undotted targets (intramodal overshadowing). A companion experiment with targets differing in odor showed the same preference for the consistently reinforced alternative in both groups (no intermodal overshadowing). The test results are plotted in Figure 15. It might be suspected that the odors employed were more salient or discriminable than the colors, but there is no support for that interpretation. Comparison of the ND-C and ND-P curves for colors (above) and odors (below) shows that the discrimination of the colors was better if anything than discrimination of the odors by animals trained with undotted targets.

If the parsimonious independence assumption must be abandoned, what can be put in its place? The principle of shared associative strength (Rescorla \& Wagner, 1972) is attractive on grounds of rigor and relative simplicity, but it provides no immediate explanation either of dimensional transfer (where the transfer occurs) or of the discrepant results obtained in experiments with intramodal versus intermodal compounds. It is instructive that even the dot-color results, which considered by themselves might seem readily understandable in terms of the Rescorla-Wagner theory, are shown not to be by formal efforts to simulate them. Extensive factorial exploration yields many sets of parameter values (the level of associative strength supported by the reward, the incremental and decremental learning rates, and the saliences of the colors and the dots) that predict substantial overshadowing by the dots in training with one color consistently re- 


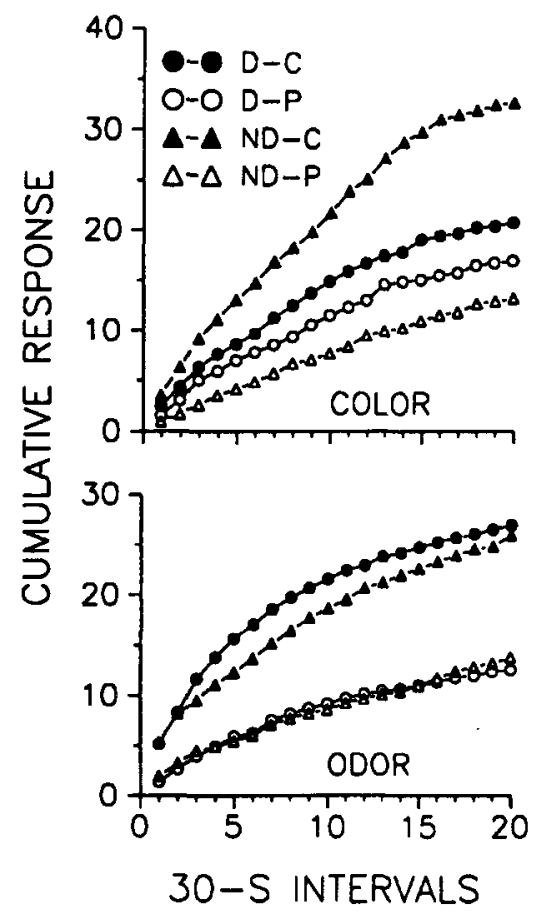

Figure 15. Cumulative number of responses in an unreinforced choice test with undotted targets differing in color (top) or odor (bottom), one consistently reinforced $(C)$ in training and the other partially reinforced $(P)$. In training, the location on each target of the small drop of sucrose used as reward (or of water on unreinforced trials) was marked with a white dot for two groups (D) but not for the others (ND).

inforced and the second entirely unreinforced (cf. Pearce \& Redhead, 1993), but none in training with the second color reinforced on half its presentations; the data, to the contrary, show overshadowing in the latter case, but not in the former (Couvillon et al., 1996). What remains is the possibility of competition for attention, which provides at least a qualitative account of dimensional transfer, and which may well be keener in intramodal than in intermodal compounds.

\section{SPATIAL LEARNING}

The work on spatial learning to be considered reflects a diversity of interests. One of them, arising out of the discrepant results for color-position and color-odor compounds in experiments on overshadowing and dimensional transfer, is in the basis of position discrimination. A second interest is in landmark learning by foraging honeybees at newly discovered feeding places, the timing of which has been taken as evidence of adaptive specialization. A third interest is in short-term memory, a topic much in the forefront of contemporary work on vertebrate learning.

In the analysis of spatial discrimination in honeybees, the vertebrate literature again provides a useful frame of reference (Restle, 1957). Trained on an elevated T-maze whose situation in a visually heterogeneous environment is changed from trial to trial, rats can learn to always go to a fixed place, whether a left or a right turn at the choice point is required to take them there on any given trial. They can also learn to always turn to the left or always turn to the right at the choice point, although the same turn takes them to different places on different trials. Learning to always turn left or right at a choice point has traditionally been characterized as "response" learning, but it seems at least equally plausible that choice is based on "position in [the animal's] visual space," as Wehner (1981) has suggested in his analysis of pattern perception in honeybees. The distinction between the discrimination of place (defined in relation to the surround) and position (defined in relation to the orientation of the animal) turns out to be useful also for honeybees (Huber, Couvillon, \& Bitterman, 1994).

Foragers were trained individually to discriminate between two identical targets on top of a large $(90 \times 180 \mathrm{~cm})$ table set in the diverse surround diagrammed in Figure 16, one of the targets (say, the one to the west) always containing sucrose and the other always containing water. When the separation of the two targets was $40 \mathrm{~cm}$, discrimination was very good. When the separation was only $10 \mathrm{~cm}$, discrimination failed if the location of the pair of targets remained the same (at the center of the table) throughout the training, but it succeeded when the location of the pair (still in the east-west orientation) was changed markedly from trial to trial. The change in location, which could not have promoted place learning, may have facilitated the development of a fixed orientation to the pair and so set the stage for position learning. With the same $10-\mathrm{cm}$ separation, discrimination also became possible when the immediate environment of the targets was enhanced as shown in Figure 17. In an effort to promote place learn-

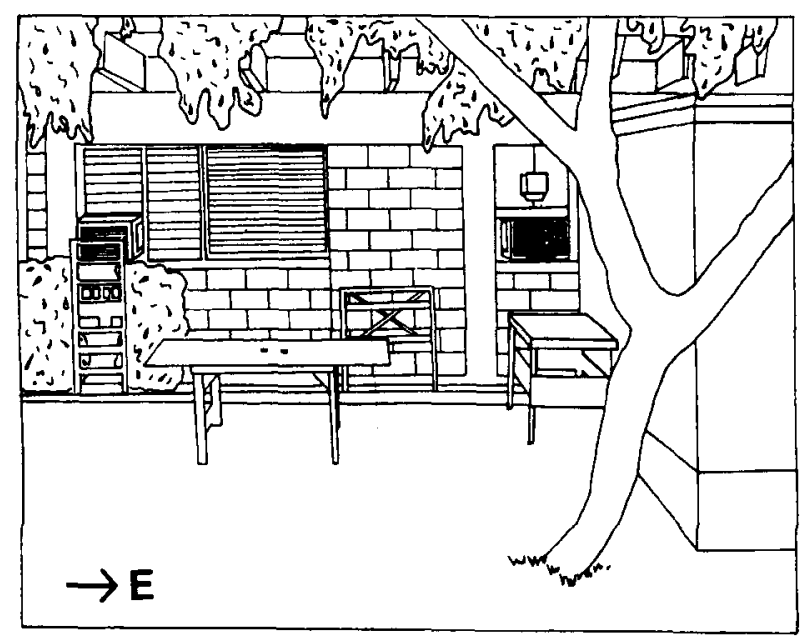

Figure 16. Sheltered outdoor setting used for the study of spatial learning in honeybees. The top of the table is $90 \times 180 \mathrm{~cm}$. 
ing, a small block (or landmark) was set at the side of one or the other of the targets. In an effort to promote position learning, a block (or bar) was introduced that did not itself distinguish the two targets but seemed in conjunction with the larger context to promote the development of a fixed orientation to the pair of targets.

That the landmark and the bar functioned differently is evidenced by the fact that discrimination was successful even when the landmark-target configuration was both displaced (its location on the table varied markedly) and rotated from trial to trial, but not when the bar-target configuration was displaced and rotated in the same way-a fixed relation between the bar-target configuration and the larger environment was essential. Discrimination was successful, too, with a high-curved shield, placed symmetrically with respect to the two targets, that was intended to exert more powerful control of the orientation to the targets than did the bar, and at the same time to minimize the influence of the larger environment. Plotted in Figure 18 are the results of unreinforced preference tests made after 16 training visits (one trial per visit with feeding to repletion as reward) under each of several conditions: $40-\mathrm{cm}$ separation of the targets alone; $10-\mathrm{cm}$ separation of the targets alone, displaced, or not; $10-\mathrm{cm}$ separation with the target-landmark configuration both displaced and rotated, or not; $10-\mathrm{cm}$ separation with the target-bar configuration both displaced and rotated, or not; and $10-\mathrm{cm}$ separation with the shield. Whether the spatial learning in the color-position experiments on overshadowing and dimensional transfer was position learning in the narrower sense of that term, or place learning, or both, is unknown, although it seems safe to assume in either case that it was visual and that the compounds therefore were intramodal. It might be well, however, to repeat the experiments in relatively pure place and position settings.

\section{LANDMARK}

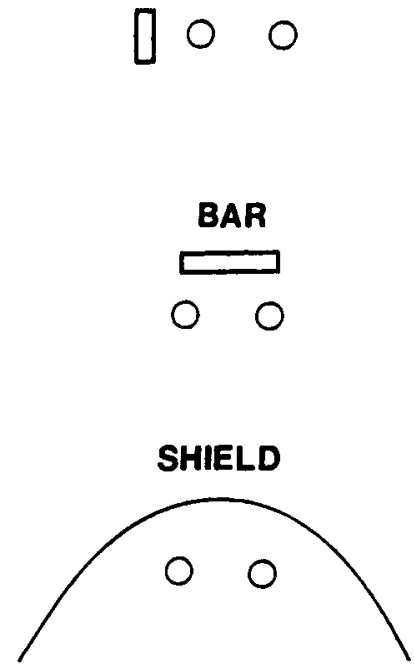

Figure 17. Objects that promoted discrimination between two targets set $10 \mathrm{~cm}$ apart on the table shown in Figure 16.

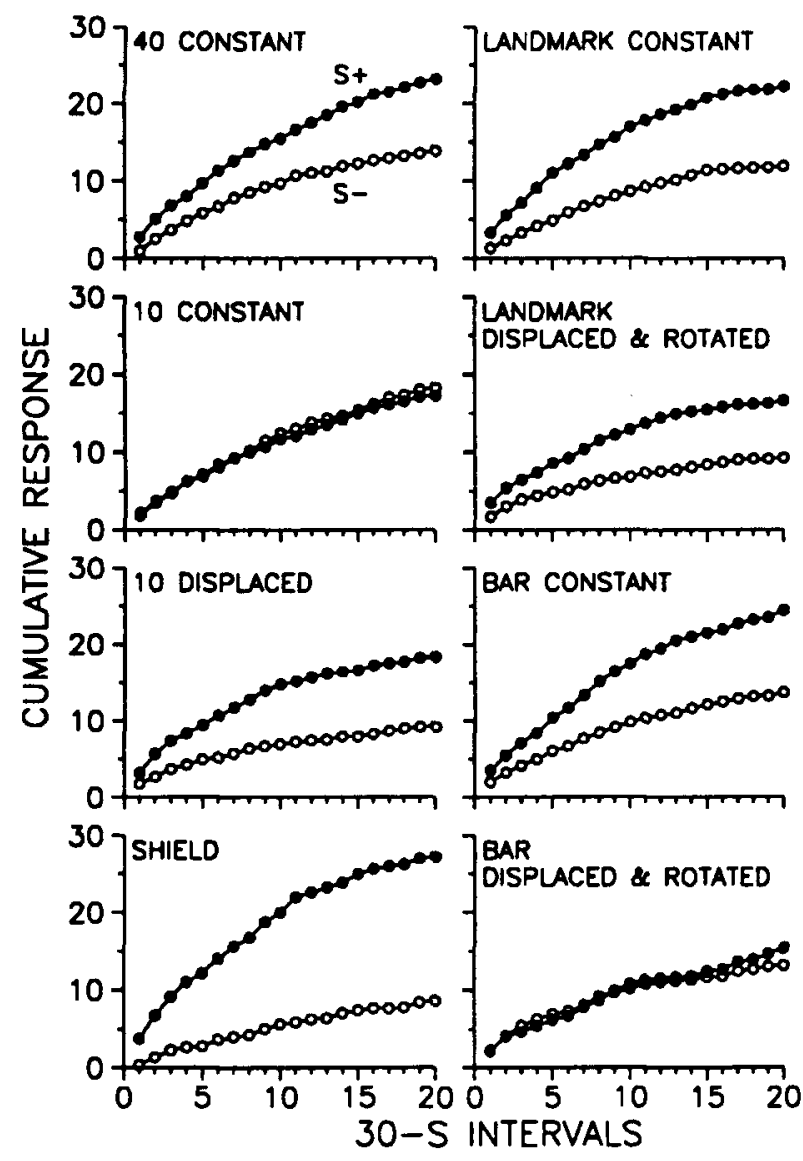

Figure 18. Cumulative number of responses in unreinforced choice tests with two identical targets differentially reinforced under various conditions: $40-\mathrm{cm}$ separation of the targets alone (40 constant); $10-\mathrm{cm}$ separation of the targets alone, constant or displaced; 10-cm separation with the target-landmark configuration, constant or both displaced and rotated; $10-\mathrm{cm}$ separation with the target-bar configuration, constant or both displaced and rotated; and $10-\mathrm{cm}$ separation with the shield.

Other recent experiments on spatial learning in honeybees have been concerned with the question of when in the course of a visit to a newly discovered feeding place a forager learns how to find it again. Although the "orientation flight" that typically precedes return to the hive after feeding at a new place would seem to provide opportunity for what Hannes (1930) early referred to as "backward conditioning," the innovative work of Opfinger (1931) led her to conclude that foragers learn about the color and shape of a feeding place and about nearby landmarks only on arrival at it - that is, only if those characteristics are perceived in advance of feeding. A contrary view, defended by Gould (1988), is that nearby landmarks are learned about only on departure, which he has taken as an indication that learning in honeybees is highly specialized. It is "logical," he has explained, that a forager should "wait" to learn about the location of a flower until determining that the flower provides food, although the same might be said of the color and shape of the flower, which according to Gould are learned about only on ar- 
rival. Gould's experiment does demonstrate learning about landmarks on departure, but not only on departure.

There is now clear evidence of learning about landmarks both on arrival and on departure (Couvillon \& Bitterman, 1992b). In the situation sketched in Figure 16, foragers were trained to choose between two identical targets set on the top of the table, one of the targets bracketed by landmarks (blue blocks) $30 \mathrm{~cm}$ to either side of it. There were four different arrangements of the targets and landmarks that were changed quasi-randomly from visit to visit. In two of the arrangements, the targets were situated on an imaginary SW-NE diagonal as shown in Figure 19, and either the SW or the NE target was bracketed. In the two other arrangements, the targets were on the NW-SE diagonal, and either the NW or the SE target was bracketed. The correct target (bracketed for half the animals and unbracketed for the rest) contained a large drop of sucrose solution from which feeding to repletion was permitted and the other contained a large drop of water. For the subjects of Group LL, the landmarks were present both on arrival and on departure, but the landmarks were removed during feeding for the subjects of Group LN (which, because of the structure of the targets, could not observe the process). In Figure 20, learning curves for the two groups are plotted in terms of the mean number of incorrect initial choices in successive blocks of four training visits. The improvement in the performance of Group LN demonstrates learning on arrival, and the significantly better performance of Group LL demonstrates learning on departure. There is evidence, too, that the color and pattern of a feeding place are learned about both on arrival and departure (Couvillon, Leiato, \& Bitterman, 1991; Lehrer, 1993).

In vertebrates, learning about stimuli that follow motivationally significant events has been demonstrated repeatedly (see, e.g., Hearst, 1989; Pinel, Mana, \& Wilkie, 1986). Its basis is not clear, although in no case need the conditioning be more than nominally backward; the critical associations may be with the sensory aftereffects of reinforcement. New experiments on proboscis-extension conditioning (Hoban et al., 1996), like those in which the

\section{BUILDING WALL}

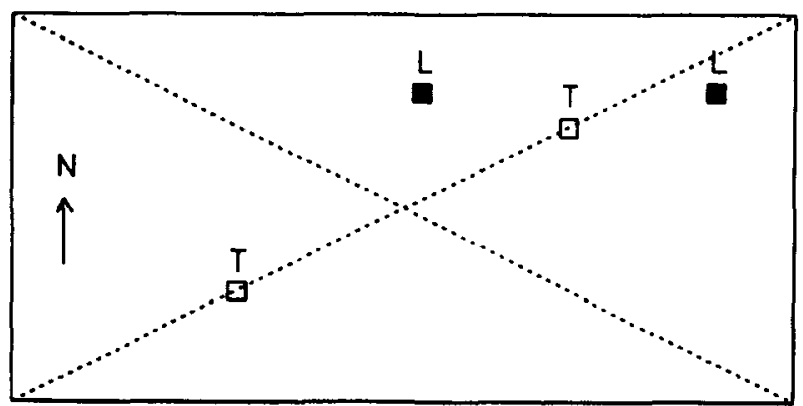

Figure 19. One of four different arrangements of targets (T) and landmarks (L) on the $90 \times 180 \mathrm{~cm}$ top of the table shown in Figure 16. The dashed diagonal lines are imaginary.

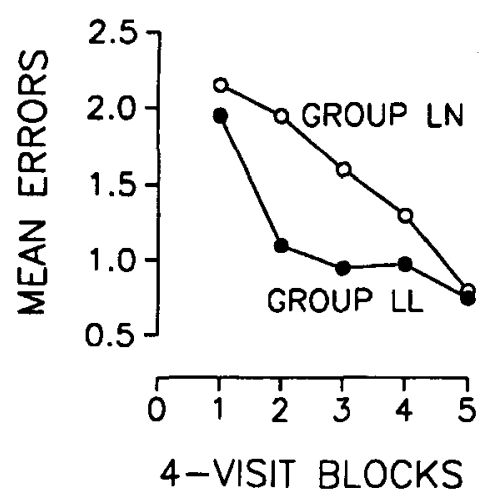

Figure 20. Acquisition curves plotted in terms of mean errors per block of visits for two groups trained to discriminate landmarks present on both arrival and departure from a feeding place (LL) or only on arrival (LN).

effectiveness of simultaneous pairing has been demonstrated (Batson et al., 1992), have failed to show any effect of backward pairing, but acceptance of the null hypothesis certainly would be premature. The results of backward conditioning experiments with vertebrates are notoriously inconsistent, varying among other things with the measure of conditioning employed (e.g., Matzel, Held, \& Miller, 1988).

The performance of honeybees has also been studied in simple analogues of the radial maze of Olton and Samuelson (1976), which has been used widely to study spatial learning in rats. The key to the performance of rats in such situations is their long-known tendencyindependently of reinforcement-to avoid places recently visited (Glanzer, 1953; Montgomery, 1952; Wingfield \& Dennis, 1934); both place learning and short-term memory are implicated (Dennis, 1939). A like tendency in honeybees has been reported recently by Brown and Demas (1994), who failed, however, to address satisfactorily some of the special requirements of work with honeybees, such as to control for their tendency to mark depleted flowers with an aversive scent (Núñez, 1967). In subsequent experiments that did meet the requirements, no tendency to avoid places that had recently been visited was found (Burmeister, Couvillon, \& Bitterman, 1995). The animals showed only some strong place and directional preferences that may have masked any short-term memory effect.

A more recent experiment on alternation or "win-shift" training with color did not indicate a reluctance on the part of honeybees to return to a location at which reward has most recently been found, but the opposite (Ohyama, Couvillon, \& Bitterman, 1995). The training was with conical targets, their interior surfaces either yellow or blue, that were presented at the three positions labeled A, $\mathrm{B}$, and $\mathrm{C}$, as shown in Figure 21. Arriving from the hive on each of 24 training visits, a subject found a single target - "a sample"-at A. The sample was yellow on half the visits, blue on the rest, and contained a small drop of 
sucrose solution. As the sucrose was being ingested, two additional targets, one yellow and the other blue, were introduced (out of sight of the animal in the sample target) at locations B and C, with the target of the same color as the sample containing a drop of water and the target of the opposite color containing a drop of sucrose. After taking the sucrose in the sample target, the animal would leave it to choose between the new targets, and in the event of error was free at once to correct its choice. Then the sample was withdrawn, the new target containing sucrose with the animal feeding in it was moved to location A where it served as the sample for the second trial, fresh yellow and blue targets were introduced at $B$ and $\mathrm{C}$, and so forth, until the animal was replete and returned to the hive.

Although the reward was for alternation, the animals showed instead a persistent preference for the positive color of the immediately preceding trial. Plotted in Figure 22 is the mean proportion of perseverative (erroneous) color choices in each block of four visits. The proportion of such choices was greater than chance at the outset of training and showed no tendency to decline as training continued. There was also substantial perseveration in the choice of location, with respect to which neither perseveration nor alternation was differentially reinforced. Plotted in Figure 22 along with the data for color is the mean proportion of trials in each block of four visits on which the animals went first to the location at which reward had been found on the immediately preceding trial. The proportion was greater than chance at the outset of training and showed no tendency to decline as training continued. The two perseverative tendencies summated, increasing the probability of error when on any trial the two colors were in the same locations as on the

\section{EXPERIMENTER \\ (INSIDE LABORATORY)}

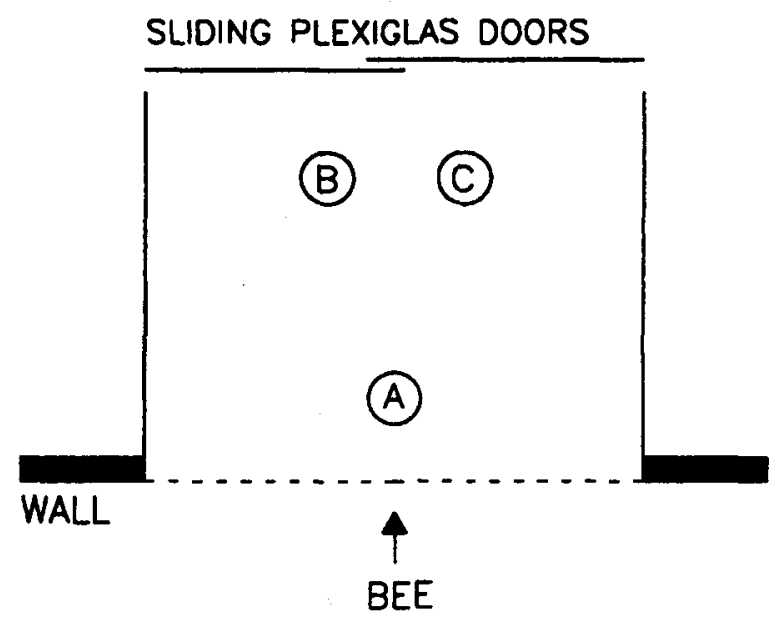

(APPROACHING FROM HIVE)

Figure 21. Diagram of an enclosure (58 cm wide) used for alternation training. Targets were placed at locations $A, B$, and $C$.

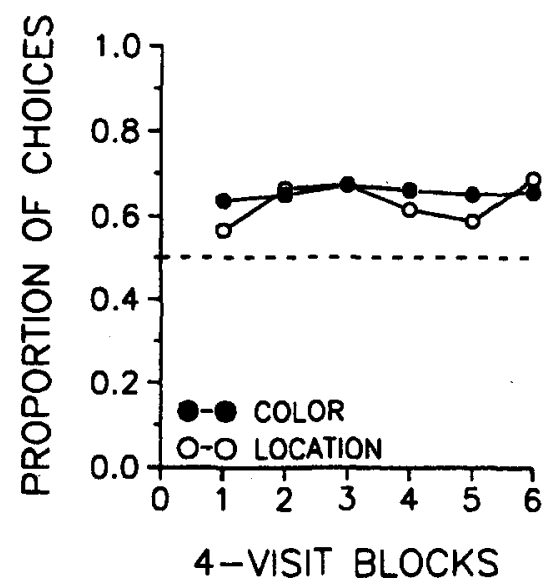

Figure 22. Mean proportion of perseverative color choices (choices of the most recently rewarded color) and perseverative location choices (choices of the location at which reward was given most recently) in successive four-visit blocks of color-alternation training.

preceding trial, and decreasing the probability of error when the locations of the two colors were interchanged.

The location effect is interesting because it is indisputably mnemonic. The choice of color might have been influenced by the color of the sample, which remained until the animal chose correctly, but at the time of choice the sample was at a central location, equidistant from both alternatives. The location effect is also interesting because it does not seem that preference for one of two alternatives should be strengthened so substantially by a single reinforcement after extensive reinforced experience with both of them (Fischer et al., 1993; Menzel, 1969). It is tempting instead to propose a supplementary mechanism that enhances the attractiveness of a location at which reward has been found (and perhaps of the color found there as well) for a brief period thereafter-a recency or short-term memory effect-such as has been suggested to deal with some analogous results for pigeons (Bailey $\&$ Mazur, 1990). In view of the evidence of divergence that has appeared in comparative experiments on the control of performance by short-term memory of reward and nonreward in vertebrates (Bitterman, 1994), the study of short-term memory in honeybees promises to be particularly instructive. For further work on the problem, it will be necessary to modify the training situation in such a way as to remove the previously reinforced color before each new choice can be made, and to permit (both in color and in location experiments) exact control of the time between the experience to be remembered and the subsequent opportunity for choice.

\section{SUMMARY AND CONCLUSION}

The performance of honeybees in a variety of experiments patterned after experiments on learning in vertebrates is strongly reminiscent of the performance of vertebrates: Asymptotic preference for a color or an odor 
paired with sucrose solution increases with the amount and concentration of the solution. The attractiveness of an odor paired with a relatively low concentration of sucrose is reduced by immediately preceding experience with a higher concentration; unrealized anticipation of a high concentration disrupts feeding and facilitates extinction. The latency of a simple instrumental response may be decreased, and its resistance to extinction increased, by the addition of unreinforced trials to the training schedule; when unreinforced trials are not added, but simply substituted for half the reinforced trials, resistance to extinction may be increased without effect on the course of acquisition. In training with two stimuli that are reinforced with different probabilities, the choice ratio varies in linear fashion with the reward ratio. Detection of weak stimuli may be facilitated by training with more salient stimuli of the same class. The components of a compound tend to be associated with each other; the presence of one component may impair conditioning of another; and the components interact to permit the solution of ambiguous-cue, compound-component, and conditional problems. Performance in the second of two discrimination problems may be better when the relevant dimension is the same in the second problem as in the first than when it is an irrelevant dimension of the first problem. Spatial learning involves both discrimination of place (defined by reference to the surround) and discrimination of position (defined by reference to the orientation of the animal); short-term as distinct from longterm spatial memory is suggested by a tendency to return to the one of two frequently rewarded locations at which food has most recently been found. Stimuli encountered immediately after feeding may be associated with the food by free-flying subjects, which also learn to leave a feeding place readily in response to a stimulus that signals impending shock. Harnessed subjects, responding with proboscis-extension to odors paired with sucrose, show simultaneous conditioning, forward (but not backward) conditioning, differential conditioning, secondorder conditioning, acquisition in omission training, and retarded acquisition after training with odor and sucrose explicitly unpaired.

Only in a small number of respects are the results for honeybees different from those for vertebrates in general. Experiments on partial reinforcement have shown neither single-alternation patterning nor greater resistance to extinction after training with longer as compared with shorter runs of $\mathrm{N}$ trials, although it would be premature (experience with vertebrates teaches) to conclude from initial failures to find such parameter-sensitive phenomena that they do not exist. Another and more impressive difference is that the results of a variety of experiments on the discrimination of intermodal (color-odor, dot-odor) compounds can be accounted for readily in terms of a simple continuity theory, but not the overshadowing and dimensional transfer found in experiments with intramodal (color-position, dot-color) compounds; the intramodal results point to competition for attention, which may simply be weaker in intermodal compounds.
More interesting than ever in the light of the honeybee results is the possibility that blocking and related phenomena in vertebrates as well as in honeybees may be understood entirely in terms of competition for attention. In any case, there is little support here for the insistent assertion of Gould $(1984,1993)$ that the learning of honeybees is highly specialized - that "evolution has acted to orchestrate and fine tune virtually every aspect [of their learning] to meet the challenges posed by their niche" (1984, p. 164). Like the old evidence of adaptive specialization in vertebrate learning (Bitterman, 1976), the evidence offered by Gould for specialization in the learning of honeybees is surprisingly sparse and does not stand up to critical scrutiny (Bitterman \& Couvillon, 1991).

A useful and plausible working hypothesis with respect to the many phenomena of learning common to vertebrates as diverse as fishes and mammals is that they reflect the operation of common functional principles, which would be understandable on the assumption of common mechanisms developed early and conserved. The same working hypothesis is also useful with respect to phenomena of learning common to honeybees and vertebrates, although less plausible perhaps on the ground that the mechanisms have evolved independently in large measure and therefore are likely to be different. It might be argued, however, that selection would have been for functional properties rather than for mechanisms, and that the range of feasible mechanisms is more limited than may at first appear; given the laws of physics and the nature of available materials, there are, as Pantin (1951) put it, only so many ways to build a bridge. Unfortunately, the road from phenomena to principles is not an easy one; after a century of research with vertebrates, there is still little agreement on such fundamental matters as, for example, the necessary and sufficient conditions for the formation of an association between two stimuli or the role of reward in instrumental training. Nor does the road from principles to mechanisms seem any less difficult.

Honeybees, whose brains are small and densely packed (Mobbs, 1982), certainly are not ideal subjects for the neurophysiological analysis of learning, although they are extremely useful for behavioral analysis, as should be evident from the research reviewed here; often it is possible in a matter of a few weeks to do a learning experiment with honeybees that with rats or pigeons would require at least as many months and be considerably more expensive as well. Although much has already been accomplished, a host of questions are waiting to be answered, and it is to be hoped that colleagues with an understanding of the rich learning literature prerequisite to fruitful comparative analysis will be tempted to join in the enterprise.

\section{REFERENCES}

Ammon, D., Abramson, C. I., \& Bitterman, M. E. (1986). Partial reinforcement and resistance to extinction in honeybees. Animal Learning \& Behavior, 14, 232-240. 
AMSEL, A. (1992). Frustration theory: An analysis of dispositional learning and memory. Cambridge: Cambridge University Press. Amsel, A., \& Roussel, J. (1952). Motivational properties of frustration: I. Effect on a running response of the addition of frustration to the motivational complex. Journal of Experimental Psychology, 43, 363-368.

BAILEY, J. T., \& MAZUR, J. E. (1990). Choice behavior in transition: Development of preference for the higher probability of reinforcement. Journal of the Experimental Analysis of Behavior, 53, 409422.

Batson, J. D., Hoban, J. S., \& BitTerman, M. E. (1992). Simultaneous conditioning in honeybees (Apis mellifera). Journal of Comparative Psychology, 106, 114-119.

BitTerman, M. E. (1960). Toward a comparative psychology of learning. American Psychologist, 11, 704-712.

BitTerman, M. E. (1975). The comparative analysis of learning. Science, 188, 699-709.

BitTerman, M. E. (1976). Issues in the comparative psychology of learning. In R. B. Masterton, M. E. Bitterman, C. B. G. Campbell, $\&$ N. Hotton (Eds.), Evolution of brain and behavior in vertebrates (pp. 217-226). Hillsdale, NJ: Erlbaum.

BitTERMAN, M. E. (1987). Evidence of divergence in vertebrate learning. Behavioral \& Brain Sciences, 10, 659-660.

BitTERMAN, M. E. (1988). Vertebrate-invertebrate comparisons. In H. J. Jerison \& I. Jerison (Eds.), Intelligence and evolutionary biology (pp. 251-276). Berlin: Springer.

BitTERman, M. E. (1994). Amsel's analysis of reward-schedule effects. Psychonomic Bulletin \& Review, 1, 297-302.

Bitterman, M. E., \& Couvillon, P. A. (1991). Failures to find evidence of adaptive specialization in the learning of honeybees. In J. L. Goodman \& R. C. Fischer (Eds.), The behaviour and physiology of bees (pp. 288-395). Wallingford, UK: CAB International.

Bitterman, M. E., Menzel, R., Fietz, A., \& Schäfer, S. (1983). Classical conditioning of proboscis extension in honeybees (Apis mellifera). Journal of Comparative Psychology, 97, 107-119.

Brown, M. F., \& Demas, G. E. (1994). Evidence for spatial working memory in honey bees (Apis mellifera). Journal of Comparative Psychology, 108, 344-352.

Buchanan, G. M., \& BitTerman, M. E. (1989). Learning in honeybees as a function of amount of reward: Tests of the equalasymptote assumption. Animal Learning \& Behavior, 17, 475-480.

Burmeister, S., Couvillon, P. A., \& Bitterman, M. E. (1995). Performance of honeybees in analogues of the rodent radial maze. $A n$ imal Learning \& Behavior, 23, 369-375.

CAPaldi, E. J. (1964). Effect of length, number of different N-lengths, and number of reinforcements on resistance to extinction. Journal of Experimental Psychology, 68, 230-239.

CAPAlDI, E. J., \& LYNCH, D. (1967). Repeated shifts in reward magnitude: Evidence in favor of an associational and absolute (noncontextual) interpretation. Journal of Experimental Psychology, 75, 226-235.

Couvillon, P. A., Asam, A. M., \& Bitterman, M. E. (1992). Further efforts at training pigeons to discriminate changes in the geomagnetic field. Journal of Experimental Biology, 173, 295-299.

Couvillon, P. A., \& Bitterman, M. E. (1980). Some phenomena of associative learning in honeybees. Journal of Comparative \& Physiological Psychology, 94, 878-885.

Couvillon, P. A., \& Bitterman, M. E. (1982). Compound conditioning in honeybees. Journal of Comparative \& Physiological Psychology, 96, 192-199.

Couvillon, P. A., \& Bitterman, M. E. (1984). The overlearningreversal effect and successive negative contrast in honeybees (Apis mellifera). Journal of Comparative \& Physiological Psychology, 98, 100-109.

Couvillon, P. A., \& Bitterman, M. E. (1985a). Analysis of choice in honeybees. Animal Learning \& Behavior, 13, 246-252.

Couvillon, P. A., \& BitTerman, M. E. (1985b). Effect of experience with a preferred food on consummatory responding for a less preferred food in goldfish. Animal Learning \& Behavior, 13, 433-438.

Couvillon, P. A., \& BitTerman, M. E. (1986). Performance of honeybees in reversal and ambiguous-cue problems: Tests of a choice model. Animal Learning \& Behavior, 14, 225-231.
Couvillon, P. A., \& Bitterman, M. E. (1987). Discrimination of color-odor compounds by honeybees: Tests of a continuity model. Animal Learning \& Behavior, 15, 218-227.

Couvillon, M. E., \& BitTerman, M. E. (1988). Compound-component and conditional discrimination of colors and odors by honeybees: Further tests of a continuity model. Animal Learning \& Behavior. 16, 67-74.

Couvillon, P. A., \& BitTerman, M. E. (1989). Reciprocal overshadowing in the discrimination of color-odor compounds by honeybees: Further tests of a continuity model. Animal Learning \& $\mathrm{Be}$ havior, 17, 213-222.

Couvillon, P. A., \& Bitterman, M. E. (1991). How honeybees make choices. In J. L. Goodman \& R. C. Fischer (Eds.), The behaviour and physiology of bees (pp. 116-130). Wallingford, UK: CAB International.

Couvillon, P. A., \& Bitrerman, M. E. (1992a). A conventional conditioning analysis of "transitive inference" in pigeons. Journal of Experimental Psychology: Animal Behavior Processes, 18, 308-310.

Couvillon, P. A., \& BitTerman, M. E. (1992b). Landmark learning by honeybees. Journal of Insect Behavior, 5, 123-129.

Couvillon, P. A., \& Bitterman, M. E. (1993). Learning in honeybees as a function of amount of reward: Further experiments with color Animal Learning \& Behavior, 21, 23-28.

Couvillon, P. A., Klosterhalfen, S., \& Bitterman, M. E. (1983). Analysis of overshadowing in honeybees. Journal of Comparative Psychology, 97, 154-166.

Couvillon, P. A., Lee, Y., \& Bitterman, M. E. (1991). Learning in honeybees as a function of amount of reward: Rejection of the equalasymptote assumption. Animal Learning \& Behavior, 19, 381-387.

Couvillon, P. A., Leiato, T. G., \& Bitterman, M. E. (1991). Learning by honeybees (Apis mellifera) on arrival at and departure from a feeding place. Journal of Comparative Psychology, 105, 177-184.

Couvillon, P. A., Mateo, E. T., \& Bitterman, M. E. (1996). Reward and learning in honeybees: Analysis of an overshadowing effect. Animal Learning \& Behavior, 24, 19-27.

Couvillon, P. A., Nagrampa, J. A., \& Bitterman, M. E. (1994). Learning in honeybees (Apis mellifera) as a function of sucrose concentration: Analysis of the retrospective effect. Journal of Comparative Psychology, 108, 274-281.

CRESPI, L. P. (1942). Quantitative variation of incentive and performance in the white rat. American Journal of Psychology, 55, 467-517.

DAVENPORT, J. W. (1970). Species generality of within-subjects reward magnitude effects. Canadian Journal of Psychology, 24, 1-7.

DENNIS, W. (1939). Spontaneous alternation in rats as an indicator of the persistence of stimulus effects. Journal of Comparative Psychology, 28, 305-312.

DENNY, M. R. (1946). The role of secondary reinforcement in a partial reinforcement learning situation. Journal of Experimental Psychology, 36, 373-389.

Durlach, P. J., \& Rescorla, R. A. (1980). Potentiation rather than overshadowing in flavor-aversion learning. Journal of Experimental Psychology: Animal Behavior Processes, 6, 175-187.

EsTES, W. K. (1957). Of models and men. American Psychologist, 12 , 609-617.

Fischer, M. E., Couvillon, P. A., \& BitTerman, M. E. (1993). Choice in honeybees as a function of the probability of reward. Animal Learning \& Behavior, 21, 187-195.

FlaherTy, C. F., Becker, H. C., \& Checke, S. (1983). Repeated successive contrast in consummatory behavior with repeated shifts in sucrose concentration. Animal Learning \& Behavior, 11, 407-414.

FRINGS, H. (1944). The loci of olfactory end-organs in the honey-bee. Journal of Experimental Zoology, 97, 123-134.

FRISCH, K. VON (1914). Der Farbensinn und Formensinn der Biene. Zoologische Jarbücher: Abteilung für allgemeine Zoologie und Physiologie der Tiere, 35, 1-182.

Frisch, K. voN (1919). Über den Geruchsinn der Biene und seine blütenbiologische Bedeutung. Zoologische Jarbücher: Abteilung für allgemeine Zoologie und Physiologie der Tiere, 37, 1-238.

Funayama, E. S., Couvillon, P. A., \& Bitterman, M. E. (1995). Compound conditioning in honeybees: Blocking tests of the independence assumption. Animal Learning \& Behavior, 23, 429-437. GILliaN, D. J. (1981). Reasoning in chimpanzees: II. Transitive infer- 
ence. Journal of Experimental Processes: Animal Behavior Processes, 7, 150-164.

Glanzer, M. (1953). The role of stimulus satiation in spontaneous alternation. Journal of Experimental Psychology, 45, 387-393.

Gonzalez, R. C., Bainbridge, P., \& Bitterman, M. E. (1966). Discretetrials lever pressing in the rat as a function of pattern of reinforcement, effortfulness of response, and amount of reward. Journal of Comparative \& Physiological Psychology, 67, 94-105.

Gonzalez, R. C., \& BitTerman, M. E. (1964). Resistance to extinction in the rat as a function of percentage and distribution of reinforcement. Journal of Comparative \& Physiological Psychology, 58, 258-263.

GooDnow, J. J. (1955). Determinants of choice-distribution in twochoice situations. American Journal of Psychology, 73, 396-403.

GoODRICH, K. P. (1960). Running speed and drinking rate as functions of sucrose concentration and amount of consummatory activity. Journal of Comparative \& Physiological Psychology, 53, 245-250.

GouLD, J. L. (1984). Natural history of honey bee learning. In P. Marler \& H. S. Terrace (Eds.), The biology of learning (pp. 150-180). Berlin: Springer

GouLD, J. L. (1988). Timing of landmark learning by honey bees. Journal of Insect Behavior, 1, 373-378.

GoulD, J. L. (1993). Ethological and comparative perspectives on honey bee learning. In D. J. Papaj \& A. C. Lewis (Eds.), Insect learning: Ecological and evolutionary perspectives (pp. 18-50). New York: Chapman \& Hall.

Grossmann, K. E. (1971). Belohnungsverzögerung beim Erlernen einer Farbe an einer Künstlichen Futterstelle durch Honigbienen. Zeitschrift für Tierpsychologie, 29, 28-41.

HANNES, F. (1930). Über die verschiedenen Arten des 'Lernens' der Honigbiene und der Insekten überhaupt. Zoologische Jarbücher: Abteilung für allgemeine Zoologie und Physiologie der Tiere, 47, 89-150.

HEARST, E. (1989). Backward associations: Differential learning about stimuli that follow the presence versus the absence of food in pigeons. Animal Learning \& Behavior, 17, 280-290.

hoban, J. S., Couvillon, P. A., \& Bitterman, M. E. (1996). Odorpreference in honeybees as a function of amount of reward: Tests of two hypotheses. Journal of Insect Behavior, 9, 121-132.

Holland, P. C., \& Rescorla, R. A. (1975). Second-order conditioning with food unconditioned stimulus. Journal of Comparative \& Physiological Psychology, 88, 459-467.

Huber, B., Couvillon, P. A., \& Bitterman, M. E. (1994). Place and position learning in honeybees (Apis mellifera). Journal of Comparative Psychology, 108, 213-219.

Hull, C. L. (1943). Principles of behavior. New York: AppletonCentury.

Ishida, M., Couvillon, P. A., \& Bitterman, M. E. (1992). Acquisition and extinction of a shuttling response in honeybees (Apis mellifera) as a function of the probability of reward. Journal of Comparative Psychology, 106, 262-269.

Ison, J. R., \& CooK, P. E. (1964). Extinction performance as a function of incentive magnitude and number of acquisition trials. Psychonomic Science, 1, 245-246.

Kehoe, E. J., Horne, A. J., Horne, P. S., \& Macrae, M. (1994). Summation and configuration between and within sensory modalities in classical conditioning of the rabbit. Animal Learning \& Behavior, 22, 19-26.

Klosterhalfen, S., Fischer, W., \& Bitterman, M. E. (1978). Modification of attention in honeybees. Science, 210, 1241-1243.

LASHLEY, K. S. (1942). An examination of continuity theory as applied to discrimination learning. Journal of General Psychology, 26, 241265.

LAWRENCE, D. H. (1952). Transfer of discrimination along a continuum. Journal of Comparative \& Physiological Psychology, 45, 51 1-516.

LeE, Y., \& BitTerman, M. E. (1990). Learning in honeybees as a function of amount of reward: Control of delay. Animal Learning \& Behavior, 18, 377-386.

LEHRER, M. (1993). Why do bees turn back and look? Journal of Comparative Physiology (A), 172, 549-563.

Loo, S. K., \& BitTERMAN, M. E. (1992). Learning in honeybees (Apis mellifera) as a function of sucrose concentration. Journal of Comparative Psychology, 106, 29-36.

Lowe, C. F., DAveY, G. C., \& HARzeM, P. (1974). Effects of reinforcement magnitude on interval and ratio schedules. Journal of the Experimental Analysis of Behavior, 22, 553-560.

Lowes, G., \& BitTERMAN, M. E. (1967). Reward and learning in the goldfish. Science, 157, 455-457.

MATZEL, L. D., Held, F. P., \& Miller, R. R. (1988). Information and expression of simultaneous and backward associations: Implications for contiguity theory. Learning \& Motivation, 19, 317-344.

McHose, J. H., \& Ludvigson, H. W. (1965). Role of reward magnitude and incomplete reduction of reward magnitude in the frustration effect. Journal of Experimental Psychology, 70, 490-495.

MENZEL, R. (1967). Untersuchung zum Erlernen von Spektralfarben durch die Honigbiene (Apis mellifica). Zeitschrift für vergleichende Physiologie, 56, 22-62.

MENZEL, R. (1969). Das Gedächtnis der Honigbiene für Spektralfarben. II. Umlernen und Mehrfachlernen. Zeitschrift für vergleichende Physiologie, 63, 290-309.

MoBBs, P. G. (1982). The brain of the honeybee Apis mellifera. I. The connections and spatial organization of the mushroom bodies. Philosophical Transactions of the Royal Society of London: Series $B$, 298, 309-354.

MONTGOMERY, K. C. (1952). A test of two explanations of spontaneous alternation. Journal of Comparative Psychology, 45, 287-283.

NEVIN, J. A., \& SHETTLEWORTH, S. J. (1966). An analysis of contrast effects in multiple schedules. Journal of the Experimental Analysis of Behavior, 9, 305-315.

NotTERMAN, J. M. (1951). A study of some relations among aperiodic reinforcement, discrimination training, and secondary reinforcement. Journal of Experimental Psychology, 41, 161-169.

NúÑEZ, J. A. (1967). Sammelbienen markieren versiegte Futterquellen durch Duft. Naturwissenschaften, 54, 322-323.

Ohyama, T., Couvillon, P. A., \& Bitterman, M. E. (1995). Perseveration in the color choices of honeybees. Journal of Insect Behavior, 8, 409-415.

Olton, D. S., \& SAmuelson, R. J. (1976). Remembrance of places passed: Spatial memory in rats. Journal of Experimental Psychology: Animal Behavior Processes, 2, 97-116.

Opfinger, E. (1931). Über die Orientierung der Biene an der Futterquelle. Zeitschrift für vergleichende Physiologie, 15, 431-487.

Pantin, C. F. A. (1951). Organic design. Advancement of Science, 8, 138-150.

Papini, M. R., Mustaca, A. E., \& Bitterman, M. E. (1988). Successive negative contrast in the consummatory responding of didelphid marsupials. Animal Learning \& Behavior, 16, 53-57.

Pavlov, I. P. (1927). Conditioned reflexes (G. V. Anrep, Trans.). London: Oxford University Press.

Pearce, J. M., \& Redhead, E. S. (1993). The influence of an irrelevant stimulus on two discriminations. Journal of Experimental Psychology: Animal Behavior Processes, 19, 180-190.

Perone, M., \& Courtney, K. (1992). Fixed-ratio pausing: Joint effects of past reinforcer magnitude and stimuli correlated with upcoming magnitude. Journal of the Experimental Analysis of Behavior, 57, 33-46.

Pinel, J. P. J., Mana, M. J., \& Wilkie, D. M. (1986). Postshock learning and conditioned defensive burying. Animal Learning \& Behavior, 14, 301-304.

RESCORLA, R. A. (1972). "Configural" conditioning in discrete-trial bar pressing. Journal of Comparative \& Physiological Psychology, 79, 307-317.

ResCorla, R. A. (1981). Within-signal learning in autoshaping. Animal Learning \& Behavior, 9, 245-252.

Rescorla, R. A., \& Colwill, R. M. (1983). Within-compound associations in unblocking. Journal of Experimental Psychology: Animal Behavior Processes, 9, 390-400.

Rescorla, R. A., \& CunNingham, C. L. (1978). Within-compound flavor associations. Journal of Experimental Psychology: Animal Behavior Processes, 4, 267-275.

RESCORLA, R. A., \& WAGNER, A. R. (1972). A theory of classical conditioning: Variation in the effectiveness of reinforcement and non- 
reinforcement. In A. H. Black \& W. F. Prokasy (Eds.), Classical conditioning II: Current research and theory (pp. 64-99). New York: Appleton-Century-Crofts.

RESTLE, F. (1957). Discrimination of cues in mazes: A resolution of the "place vs. response" question. Psychological Review, 64, 217-228.

Seward, J. P., Pereboom, A. C., Butler, B., \& Jones, R. B. (1957). The role of prefeeding in an apparent frustration effect. Journal of Experimental Psychology, 54, 445-450.

SHEFFIELD, V. F. (1949). Extinction as a function of partial reinforcement and distribution of practice. Journal of Experimental Psychology, 39, 511-526.

SHEPP, B. E., \& EIMAs, P. D. (1964). Intradimensional and extradimensional shifts in the rat. Journal of Comparative \& Physiological Psychology, 57, 357-361.

SHINoda, A., \& BitTerman, M. E. (1987). Analysis of the overlearningextinction effect in honeybees. Animal Learning \& Behavior, 15 , 93-96.

Simpson, G. G. (1964). Organisms and molecules in evolution. Science, 146, 1535-1538.

SMith, B. H., \& CoBEY, S. (1994). The olfactory memory of the honeybee Apis mellifera. Journal of Experimental Biology, 195, 91-108.

STADDON, J. E. R. (1970). Effect of reinforcement duration on fixedinterval responding. Journal of the Experimental Analysis of Behavior, 13, 9-11.

Sutherland, N. S., \& Mackintosh, N. J. (1971). Mechanisms of animal discrimination learning. New York: Academic Press.

Tyler, D. W., Wortz, E. C., \& Bitterman, M. E. (1953). The effect of random and alternating partial reinforcement on resistance to extinction in the rat. American Journal of Psychology, 66, 57-65. von Fersen, L., Wynne, C. D., Delius, J. D., \& Staddon, J. E. (1991) Transitive inference formation in pigeons. Journal of Experimental Psychology: Animal Behavior Processes, 17, 334-341.

WALKER, M. M., Baird, D. L., \& BitTerman, M. E. (1989). Failure of stationary but not of flying honeybees (Apis mellifera) to respond to magnetic field stimuli. Journal of Comparative Psychology, 103, 62-69.

Walker, M. M., \& BitTerman, M. E. (1989). Honeybees can be trained to respond to very small changes in geomagnetic field intensity. Journal of Experimental Biology, 145, 489-494.

WALKer, M. M., LeE, Y., \& BitTerman, M. E. (1990). Transfer along a continuum in the discriminative learning of honeybees (Apis mel. lifera). Journal of Comparative Psychology, 104, 66-70.

WEHNER, R. (1981). Spatial vision in arthropods. In H. Autrum (Ed.), Comparative physiology and evolution of vision in invertebrates. C: Invertebrate visual centers and behavior II (pp. 287-616). Berlin: Springer.

Whitlow, J. W., JR., \& WAGNER, A. R. (1972). Negative patterning in classical conditioning: Summation of response tendencies to isolable and configural components. Psychonomic Science, 27, 299301.

WINGFIELD, R. C., \& DENNIS, W. (1934). The dependence of the rat's choice of pathways upon the length of the daily series of trials. Journal of Comparative Psychology, 18, 135-147.

(Manuscript received March 23, 1995 ; revision accepted for publication May 12,1995.) 